\title{
THE HEAT PATHS IN ELECTRICAL MACHINERY.
}

\author{
By Harold D. Symons, Associate Member, and \\ Miles Walker, Member.
}

(Paper firsl received 9 th November, reccived in final form 29th November, I9I I. Read before THE INSTITUTION on 25th Famuary, I9I2, and before the MANChester local Section i2th December, I9I2.)

\section{SUMMARY.}

The paper deals witl methods of predetermining the temperature rise in electric machinery. Data are given of the heat conductivity of insulating materials. The methods of carrying away heat by the circulation of air are discussed, and there is given an account of experiments made to determine the amount of heat absorbed by air un fer various conditions as to temperature and velocity in passing over coils and through ventilating ducts. The heat conductivity of punchings in actual machines is also considered.

If we wish to get the largest possible output from an electric generator or motor of given cost we must make a very close study of the possible methods of carrying away the heat which is produced in the iron and copper. The heat produced in any part (be it from $I^{2} R$ loss or iron loss) has a definite path from the point of origin to the place where it is thrown out from the machine. Thus some of the $I^{2} R$ losses in the armature conductors may have only to pass through a certain thickness of insulation to the air surrounding the coils, while the heat generated in the copper in the slots passes through the insulation to the iron where it meets with the heat produced in the iron, and both together are conducted to the ventilating ducts and carried by the air to the exterior.

We can imagine lines of heat-flow drawn through the machine which follow everywhere the paths of the heat from the point of origin to the point of discharge. At some points there may be constrictions in: the path which it is desirable to avoid, at others the heat stream flows easily without undue temperature gradient. Everywhere at right angles to the lines of heat flow we can imagine isothermal surfaces constructed which enclose the points of highest temperature.

If we are to even out these surfaces and lower the maximum temperatures, we must consider closely all the methods by which the heat is conveyed, whether it be by conduction, convection, or radiation. 


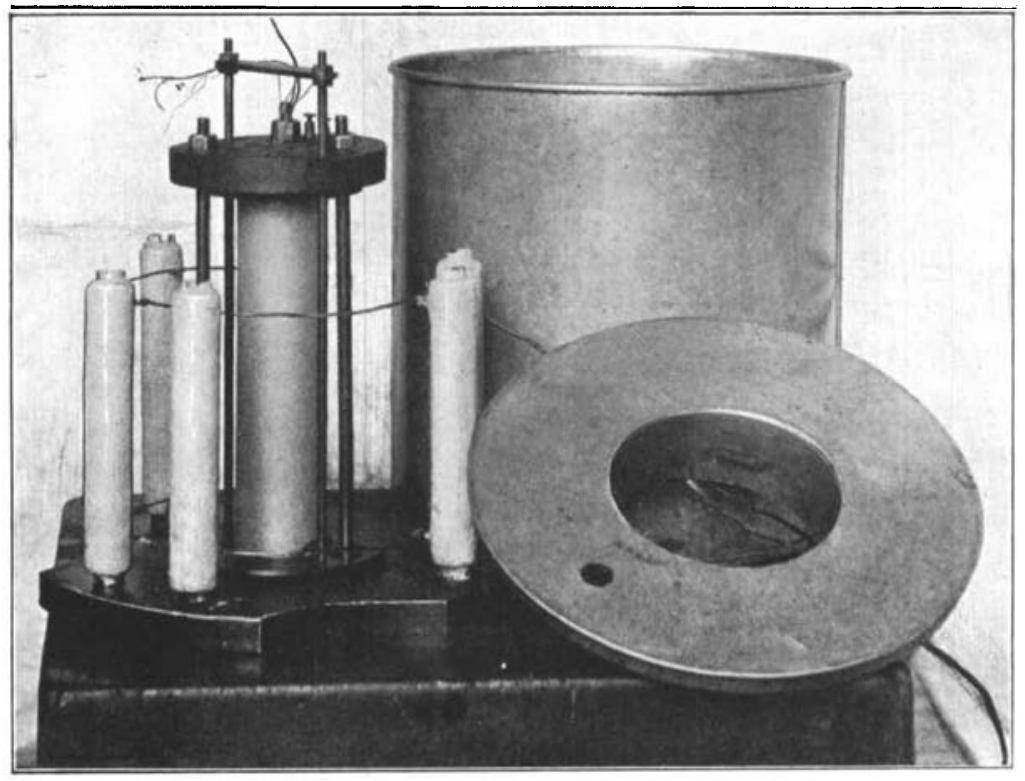

FIG. I.-Apparatus for measuring Heat Conductivity. 

The metals being good conductors, any heat produced in a mass of copper or iron distributes itself easily over the whole mass, but the insulating materials being poor heat conductors of ten cause excessive temperatures within the coils they enclose. It is desirable that the designer should have specific data as to the heat conductivity of every part of the machine in order that he may know what difference of temperature to expect between any two points in the heat path.

A good deal of useful work has been done on the measurement of temperatures inside shunt coils,* on the heat conductivity of iron punchings $\dagger$ at right angles to the plane of lamination and along the laminations; on the passage of heat from revolving cylinders + to the surrounding air and on the passage of heat from various kinds of surfaces to air ; but the authors have not been able to find any direct data on the heat conductivity of electric insulating materials mounted in the same way as one usually finds them in electrical machines. They therefore thought that it would be worth while to make measurements both of the specific conductivity of the cornmonly employed insulating materials and of the effect on the conductivity of introducing the air-spaces and gaps such as are often unavoidable in electrical machines.

Two classes of tests were made. First a test by means of laboratory apparatus on the specific heat conductivity of materials mounted in different ways. Secondly, tests made on electric generators under actual running conditions.

\section{The Heat Conductivity of Electric Insulation.}

For measuring the heat conductivity of materials in flat sheets probably the best method $\S$ is that employed by $\mathrm{Mr}$. Bacon. This method was used by the authors for pure mica and for presspahn. But where the heat conductivity of wrappings of tape and wire are to be measured it is more convenient to adopt a type of apparatus like that depicted in Figs. $\mathrm{I}$ and 2.

The materials $I-I$ are wrapped on a long copper cylinder $2-2$ and the heat passed from the inside through the insulation to an oil bath 3-3 on the outside. The temperature of the outside of the cylinder of insulation is measured by thermo-couples placed in shallow channels in the copper surface of the cylinder, the wires from the thermo-couples being brought out to the top of the apparatus, shown at $4-5-6$. The temperature of the outside of the insulation is measured by thermo-couples placed

* E. H. Rayner, "Report of Temperature Experiments," Fonrnal of the Institution of Electrical Engineers, vol. 34, p. 6I3, I905. G. A. Lister, "Heating Coefficient of Magnet Coils," ibid., vol. 38, p. 399, I907.

$千$ O. Ludivig, Mittcilung and Forschungsarbeilen, Heft 35 and 36, p. 53. T. M. Barlow, "Heat Conductivity of Iron Stampings," Fournal of the Institution of Elcctrical Engineers, vol. 4), p Gor, rgoS. R. D. Gifford, "Influence of Various Cooling Media upon the Rise in Temperature of Soft Iron Punchings," Fonrnal of the Institution of Electrical Engineers, vol. 44, p. 753, I0 Io.

+ E. Hinlein, Zeitschrift des Vereines Dentscher Ingenienre, vol. 55 , p. 730, ro r r.

$\S \mathrm{F}$. Bacon, "The Testing of Heat Insulating Materials," Enginecring, vol. 9o, p. 396 , I9ro. 
between the outside surface and a sheet of copper which was tightly wrapped around the whole. The insulation is thus placed between two surfaces of known temperature under conditions which can be made to imitate as closely as we like the conditions obtaining in the slots of electric machines.

The heat is supplied to the inside of the copper tube by means of a resistance coil 7 , embedded in asbestos insulation. This resistance coil is concentric with the copper tube, and the space between them is filled with tin solder which serves to conduct the heat to the copper. The inside surface of the tube was tinned before pouring in the melted

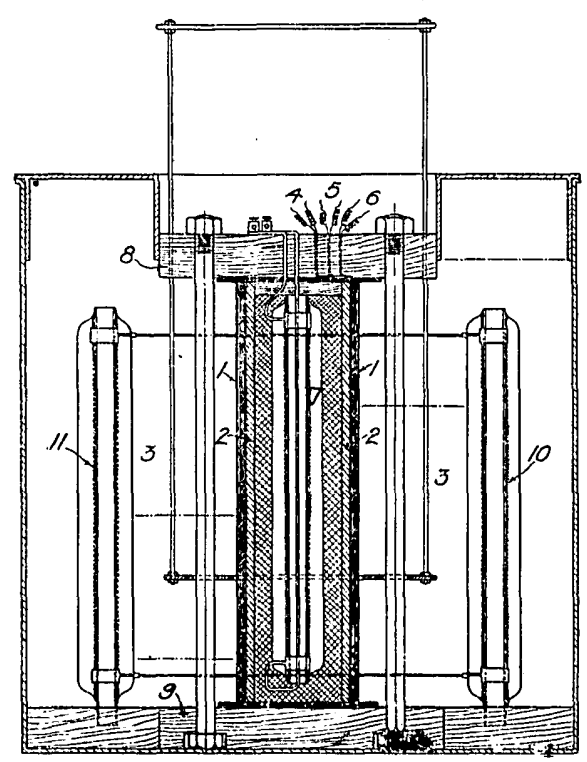

FIG. 2.-Section of Apparatus for Measuring Heat Conductivity.

solder to ensure a perfect and uniform junction of the metals. A thick copper tube heated in this way maintains itself at a fairly uniform temperature over the greater part of its surfacc even though the cooling conditions of various parts differ considerably.

The ends of the copper tube are flanked with leather washers and two thick cheeks of treated wood ( 8 and 9$)$, to minimise the escape of heat. It is calculated that the loss of heat at the ends is equal to oor 5 calorie per second per degree of difference between the inside and outsicle temperatures. In most of the experiments this amounted to about $3 \frac{1}{2}$ per cent. of the total heat flux, so that even if there is a considerable error in the estimation of this end loss the final error clue to this cause is not more than $\frac{1}{2}$ per cent. 
In some of the experiments the copper tube and insulation were immersed in a bath of oil which was well stirred during the whole of the test so as to keep the outside of the insulation at as uniform a temperature as possible. The oil was contained in a large tank which offered a cooling surface of $75^{\circ}$ sq. in., so that it would radiate all the heat supplied without an excessive rise in temperature. A number of resistance coils ro-I I were inserted in the oil, and by means of these the temperature of the oil could be maintained at any required value. These resistances are also of use in shortening the time taken to arrive at a steady state in the temperature distribution. If, for instance, it is intended in any particular experiment to supply a total of Ioo watts, then as we know from previous tests that the tank will finally settle down at $25^{\circ} \mathrm{C}$. above the air temperature, the tank is brought up quickly to $25^{\circ} \mathrm{C}$. by a large current through the resistances, and as soon as the temperature is reached the current is cut down to the value which keeps the temperature steady.

The method then of carrying out a test on any insulating material is as follows: The material is wrapped around the copper cylinder, the thermo-couples for measuring the temperature of the outside are then fixed and wrapped over with the exterior copper sheet, the insulation is trimmed off the ends of the cylinder so as to fit well against the leather washers, the two wooden cheeks are fitted to the end of the cyclinder and held firmly by long bolts. The whole is then immersed in the oil tank and the wires to the various couples connected to a multi-way switch and to the cold thermo-couple immersed in a bath of oil whose temperature is kept steady and measured by means of a thermometer. The difference of temperature between the hot and cold junctions was measured by one of R. W. Paul's millivoltmeters. This instrument, with a suitable resistance in circuit, will give the temperature in ${ }^{\circ} \mathrm{C}$. direct if we employ couples composed of metals such as iron and eureka which have an almost straight-line law over the range covered by the experiments. A known current at a known voltage is then passed through the resistance coil inside the copper tube, and the temperature of the oil in the bath is raised to the point at which it will remain steady under the conditions of the experiment. Readings of the temperature are taken at frequent intervals, and when they are found to be steady we know that the heat is being conclucted through the insulation at the same rate as it is being supplied. The total heat flow through a certain area and thickness of insulation being known, and the difference of temperature at the two sides being known, the thermal conductivity can be calculated.

In other experiments the copper tube and insulation were placed in a wooden frame by means of which two draughts of air could be blown on to the material under test from opposite sides, as indicated in Fig. 3. A photograph of the apparatus is shown in Fig. 4. The intensity of the draught of air was measured by means of anemometer and checked by measurements of the temperature of the air going in and the air 


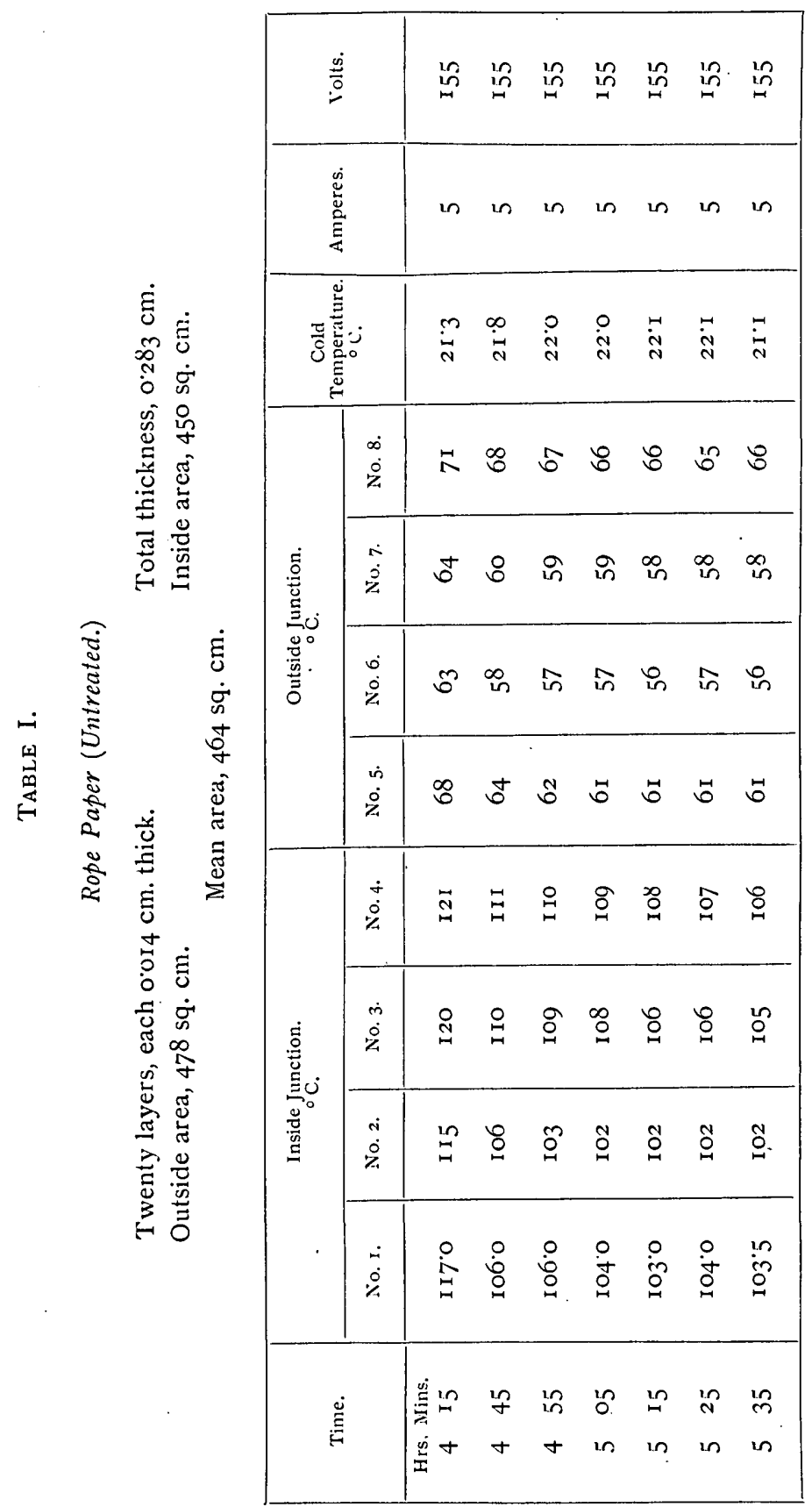


coming out. This apparatus, besides giving measurements of the heat conductivity of insulation, gives us specific data for the cooling of surfaces when subjected to a draught of this kind under conditions somewhat resembling the conditions obtaining in some electrical machines.

Table I. gives a typical set of readings for one test, and shows the degree of variation occurring in the different couples from time to time.

Table II. gives the heat conductivity of various insulating materials as measured in the manner described. The first and second columns give the material and the state in which the material was tested. The third column gives the thickness of the piece under test; the fourth

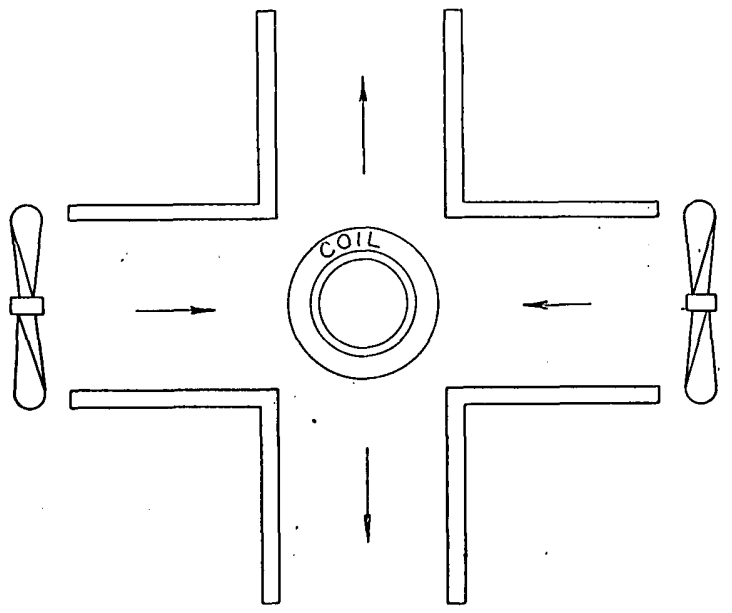

FIG. 3.-Plan of Apparatus for Cooling Coils or Rolls of Insulation by means of a Current of Air.

and fifth the temperatures of the inside and outside of the insulating tube; the sixth the mean temperature; the seventh the watts per square centimetre of surface; the eighth the heat conductivity in gram calories of a centimetre cube of the material per ${ }^{\circ} \mathrm{C}$. difference of temperature between opposite faces of the cube. The ninth column gives the conductivity expressed in watts per square centimetre, and the tenth column gives the watts per square inch passing through a I in. cube of the material for $\mathrm{I}^{\circ} \mathrm{C}$. difference of temperature between opposite faces of the $I$ in. cube.

It was found that all the cellulose materials such as cotton, paper, etc., had a considerable temperature coefficient. The heat conductivity at a temperature of $100^{\circ}$ being about 12 per cent. higher than at $30^{\circ} \mathrm{C}$. The heat conductivity of mica was not found to change between $20^{\circ}$ and $100^{\circ} \mathrm{C}$. 
Of all the fibrous materials commonly used in insulation the one having the highest thermal conductivity is empire cloth pressed into a solid mass free from air-spaces. This is probably because the fibres of the empire cloth are completely filled with oxidised varnish, whereas many of the papers, even when closely compressed, contain air-spaces.

The difference in the conductivity obtained by winding the insulation on the copper cylinder very tightly and by winding it on loosely was very marked.

It was found that micanite built up in the form of tubes containing about I I per cent. of shellac has a very poor conductivity as compared with pure mica.

Effect of Air-space in causing Resistance to Passage of Heat.

Very often a field coil insulated on the inside with layers of insulating material does not fit tight upon the pole, so that a short

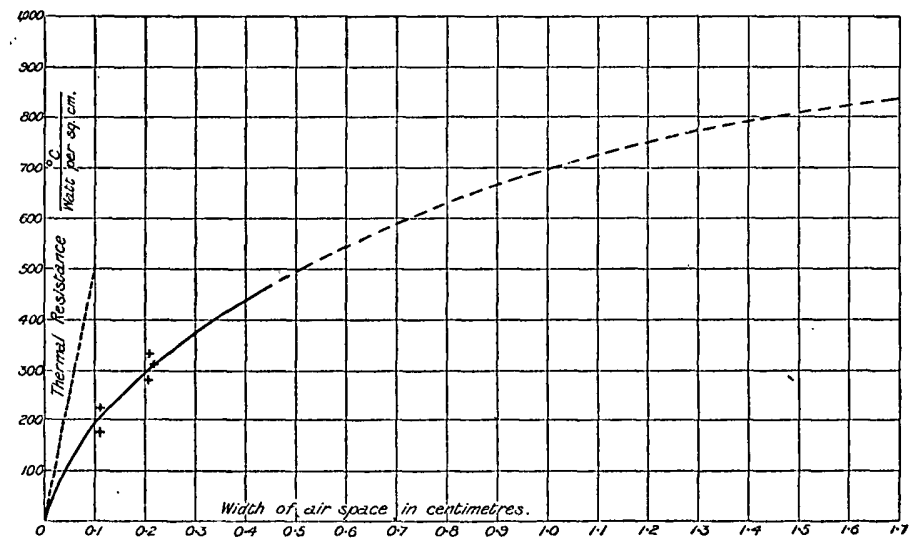

Fig. 5-Thermal Resistance of Air-spaces of Different Thicknesses.

air-space exists between the insulation and the iron of the pole. It is interesting to inquire how far this air-space hinders the passage of heat.

A number of experiments were made, in which air-spaces of different thicknesses were made between the copper tube in the testing apparatus and the insulating tube. These spaces were made by winding twine of different thicknesses in a wide spiral round the tube, and then winding the insulating material above the spiral. The thickness of the twine gave approximately the size of the air-space. It is to be expected that a very narrow air-space will have a greater thermal resistance per centimetre of thickness than a wider air-space, and as the space is widened out we come at last to a constant resistance for I sq. $\mathrm{cm}$. area of surface) which is the reciprocal of the cooling 


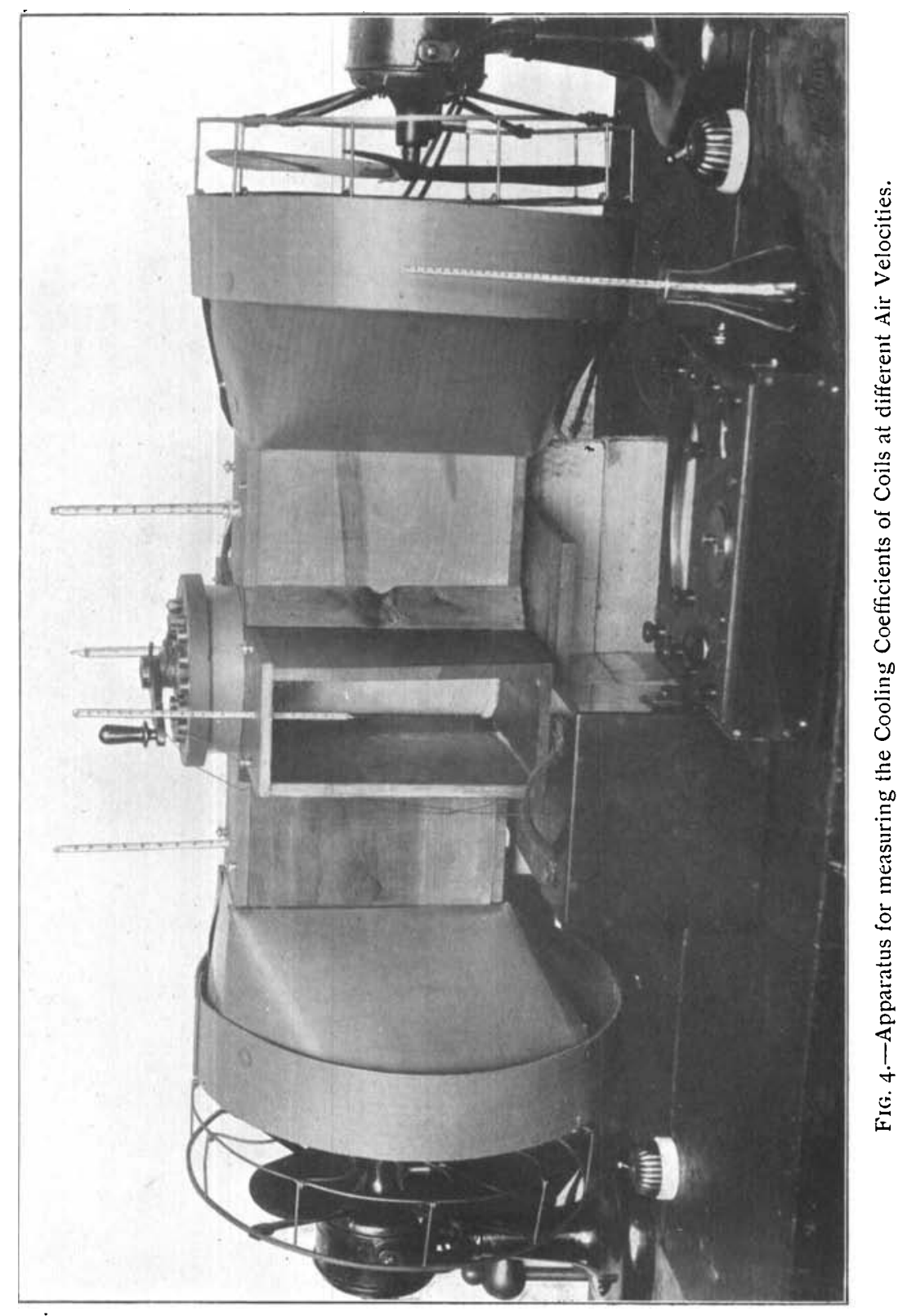



constant $(h=0 \cdot 00 \mathrm{I})$ for surfaces exposed to still air. The values obtained by our experiments do not agree very well with one another, as will be seen from Fig. 5, in which they are plotted. Still we may arrive at a fairly correct curve by the following method :-

The thermal conductivity of perfectly baffled air is 0.0002 watt per cubic centimetre per degree, so that the resistance of $\mathrm{I} \mathrm{sq.} \mathrm{cm}$. of air-

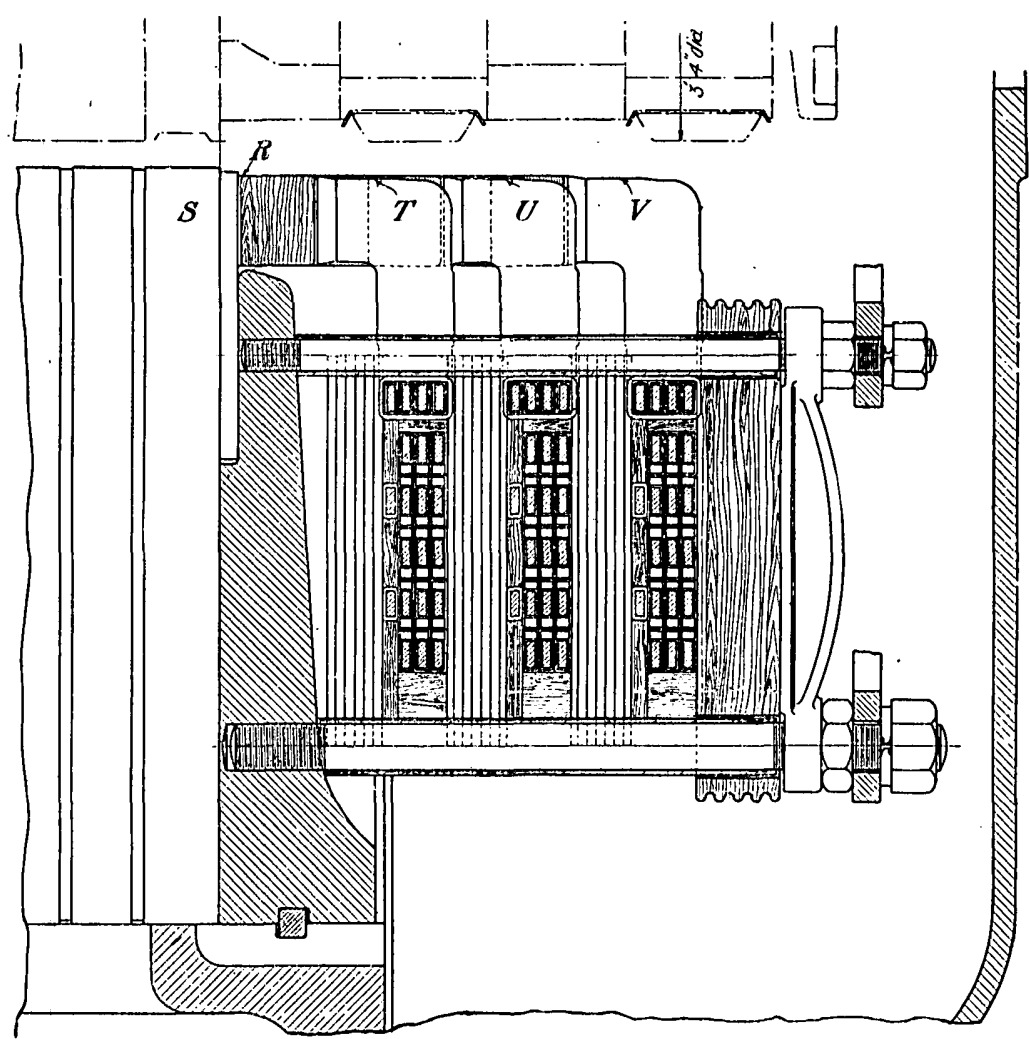

Fig. 6.-Positions of Thermo-couples for Test on the Heating of Armature Coils.

space I mm. thick would be 500 . Here the units are chosen so that the thermal resistance has the same value as the difference in temperature, at the opposite sides of the space, divided by the watts per square centimetre passing across the space. If, therefore, we draw the dotted line shown in the figure through zero to the point 500 for an air-space $\mathrm{I} \mathrm{mm}$. that line must be a tangent to the correct curve. Taking the points indicated by our tests as a guide and remembering that the curve must 
be asymptotic to the horizontal line at the value $900\left(\frac{\mathrm{I}}{\mathrm{O}^{\circ} \mathrm{OOII}}\right)$ we get the curve shown. There is no doubt that for wide air-spaces the resistance will depend. on whether the space is vertical or horizontal,* and if vertical it will depend on the number of horizontal baffles. In our case the air-spaces were vertical and the pieces of twine which would have acted as baffles were spaced about $\frac{1}{2}$ in. apart.

Let us now see how this curve can be employed in practice. Suppose that we have a field coil which is insulated on the inside next the pole with treated fuller board of a thickness of $0.2 \mathrm{~cm}$. From Table II. we find the thermal conductivity of this material (in watts per square centimetre, etc.) is o'00I4. The thermal resistance of $\mathrm{r}$ sq. $\mathrm{cm}$. is therefore $0.2 \div 0.0014=142$, so that if there were no air-space and we were passing to the pole $0^{\circ}{ }^{\prime} 5$ watt per square centimetre the difference in temperature of pole and coil would bc only $2 \mathrm{I}^{\circ} 3^{\circ} \mathrm{C}$. If now we introduce an air-space of $\mathrm{I} \mathrm{mm}$. whose resistance from Fig. 5 is about 200, the total resistance is raised to 342 and the difference in temperature for the same heat-flow would be $5^{1} 5^{\circ} \mathrm{C}$.

\section{Experiments on Machines.}

Heating of Armature Coils.-A test was made on a 5,000-k.w. 3 -phase generator by means of thermo-couples placed in the armature coils during the course of construction. Fig. 6 shows the arrangement of the armature coils; the position of the thermo-couples is indicated by the letters $\mathrm{R}, \mathrm{S}, \mathrm{T}, \mathrm{U}, \mathrm{V}$. Junction $\mathrm{R}$ gave the temperature of the copper inside the slot; $S$ the temperature of the iron surrounding the slot; $\mathrm{T}$ the temperature of the outside of the coil on the part exposed to the air; $U$ the temperature of the copper in part of a coil projecting 6 in. from the iron; $V$ the temperature of the copper in part of a coil projecting $9 \mathrm{in.}$ from the iron. The generator was run at full speed with the armature short-circuited, the field current being increased until the armature current was 328 amperes. The run was continued until the temperatures of all parts were constant. The table below gives the degrees rise above the temperature of the air admitted to the machine $\left(23^{\circ} \mathrm{C}\right.$.).

$$
\begin{gathered}
{ }^{\circ} \mathrm{C} . \text { Rise. } \\
\mathrm{R}=39^{\circ} \mathrm{O} \\
\mathrm{S}=18^{\circ} 4 \\
\mathrm{~T}=24^{\circ} 6 \\
\mathrm{U}=38^{\circ} \circ \\
\mathrm{V}=34^{\circ} 4
\end{gathered}
$$

Fig. 7 gives the arrangement of the conductors and insulation in the slot. It is drawn full size. Each conductor, which consisted of two copper straps each 0.45 in. $\times 0.2$ in., was insulated with tape and mica, a piece of mica $0^{\circ} 03$ in. thick being added as a spacer. All four

* F. Bacon, Engincering, vol. 90, p. 396 , 19ro. He found that an air-space $I \frac{1}{2}$ in. wide had ạ resistançe twice as grẹt whẹn horizontal as whẹn vẹtịicạl, 


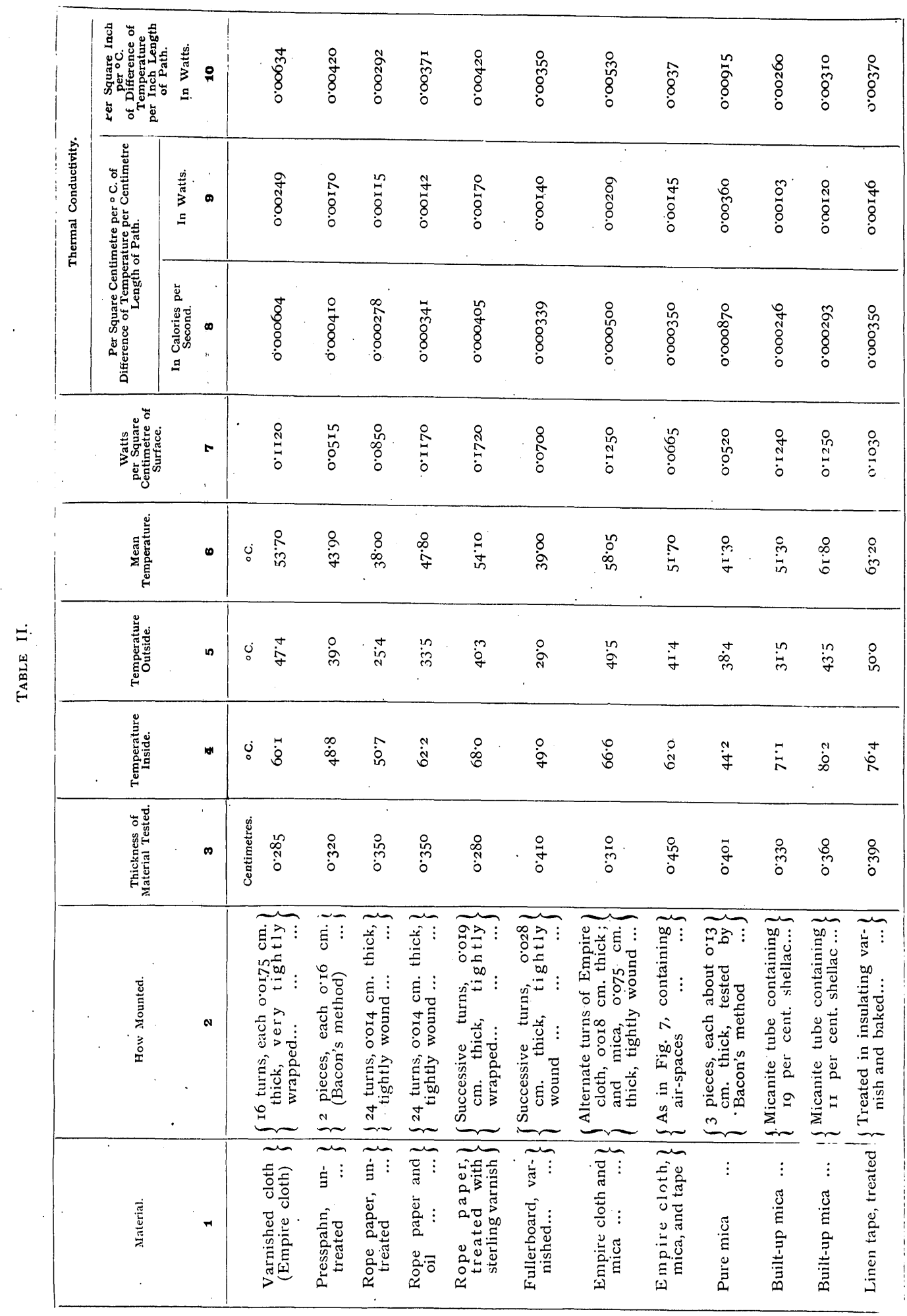



conductors were impregnated with gum and wound over with empire cloth and mica to a thickness of 0.13 in. The whole was then wound with linen tape: The total thickness of insulation amounted to $0.177 \mathrm{in}$. The various insulating materials were then present in the following proportions: Empire cloth, $0.07 ;$ mica, 0.03; varnish and air, 0.02 ; paper, 0.017 ; tape, 0.04 . The heat conductivity of the insulation is easily calculated from the above figures. The total loss in the copper conductors per foot run of coil was $27^{\circ} 2$ watts. In calculating this, allowance has been made for the rise in temperature of the copper due to the eddy currents * produced in the conductors. The difference of temperature between the copper and iron is $20^{\circ} 6^{\circ} \mathrm{C}$, and the

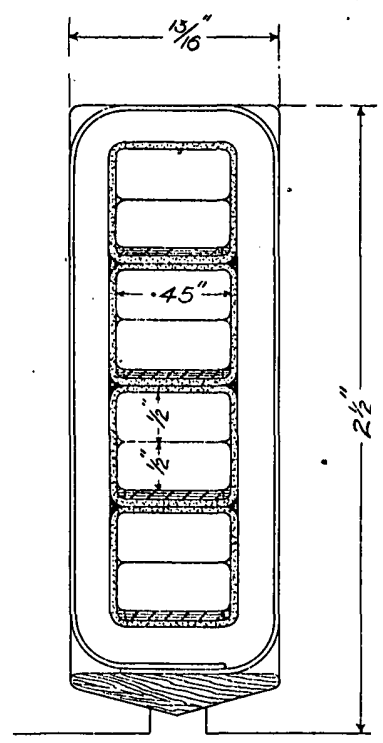

FIG. 7.-Arrangement of Insulation in Heat Conductivity Test.

mean perimeter 5.3 in., so that the total area of insulation per foot run is $63^{\circ} 5$ sq. in. With $27^{\prime 2}$ watts per foot run this gives just over 2.34 sq. in. per watt. The specific conductivity for heat of the insulation works out at $0.00 \mathrm{r} 45$ watts per centimetre cube per degree. This conductivity is considerably lower than the figure ( $\left.0^{\circ} \mathrm{OO} 2\right)$ found from tests on empire cloth and mica wound on a copper cylinder with the fewest possible air-spaces, as can be easily understood.

With coils of rectangular section wrapped with empire cloth and mica, or paper and mica, in the ordinary method, one may expect to have a heat conductivity not higher than 0.00I45 watt per cubic

* A. B. Field, Transaclions of the Amenerican Institute of Electrical Engineers, vol, 24, p. 761, I905. 
centimetre per degree. This figure is uscful in enabling us to calculate the difference of temperature between the copper conductors in a slot and the surrounding iron, and checks very well with other results found in practice. For instance, on the armature of a directcurrent generator whose conductors were insulated with manilla paper and mica to a thickness of $0 \cdot 16 \mathrm{~cm}$. The temperature rise after a fullload run under conditions which made the square inches per watt $0^{\circ} 9$, were as follows: Internal copper, $4 \mathrm{I}^{\circ}$; iron, $22^{\circ}$. If we use the figure 0.00145 watts per cubic centimetre per degree, we would obtain a temperature rise of copper above iron of $16^{\circ}$.

\section{Conduction of Heat along Conductors.}

It sometimes happens that the copper conductors on an armature or field magnet are grouped together so closely that very little air can circulate between them, and the total cooling surface of the group is ton small to dissipate the heat generated in it. In this case one relies mainly for cooling upon the conduction of heat along the conductors to parts of the coils where the cooling conditions are better. A good illustration of this case is offered by the end windings of a two-pole field magnet for a turbo-generator, such as is shown in Fig. 8. These end windings are completely covered in by a steel end-bell, so that in any case the air would not circulate well between individual coils, and to avoid the accumulation of dirt it is sometimes found advisable to fill the interspaces with suitable insulation. A great proportion of the heat generated in these end windings is conducted along the copper into the parts of the coils lying in the slots, and from thence it is conducted into the iron of the field magnet.

The flow of heat from the centre of the coil to the cooler parts can only occur if there is a considerable temperature gradient in the end windings. It is necessary sometimes to calculate what this temperature gradient will be, and what the maximum temperature rise will be in the centre of the group. The problem is somewhat complicated by the fact that the resistance of copper changes with temperature, and one ought to take account of this change of resistance because it makes the watts lost increase according to a compound interest law. Moreover, in most cases that arise in practice, part of the heat is radiated from the surface of the coils, and part is conducted along them.

We will first take the case where a conductor is so surrounded by other conductors at the same temperature as itself that the whole of the heat generated in it is conducted to the cooler ends, and none passes to the sides. Afterwards we will take the case where a considerable fraction of the heat passes out to the sides and remainder along the conductor.

Let $M$ be the centre point of a symmetrically situated end cennector so surrounded by other conductors that all the heat generated by electric current in it passes to the ends. $M$ is supposed to be the hottest point, and from it heat flows to the right and to the left as 


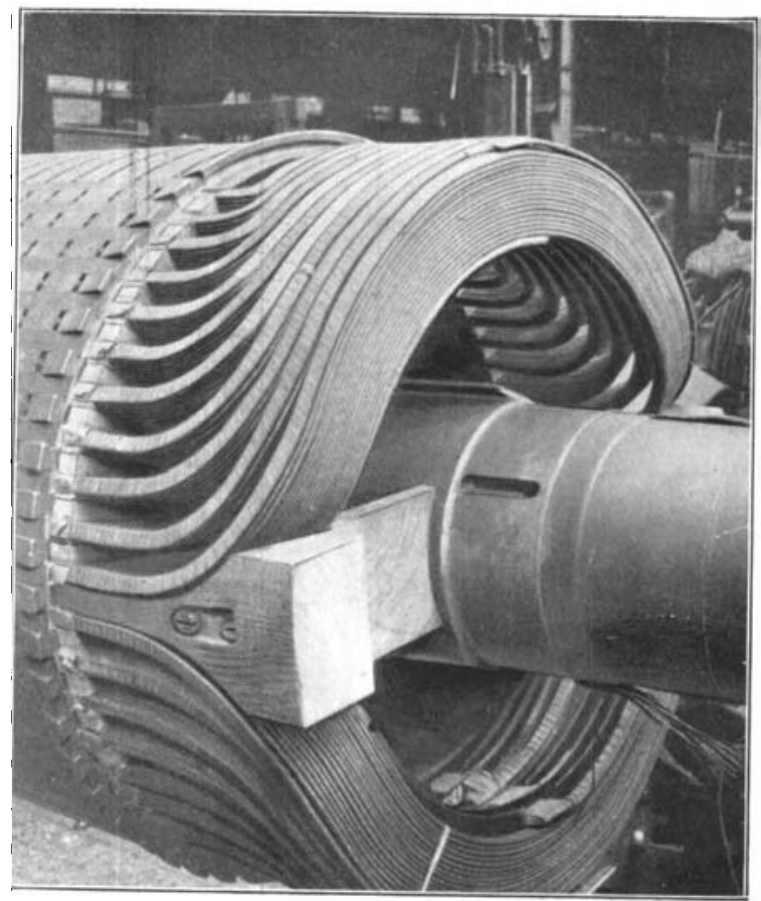

FIG, 8.-End Windings of Two-pole Turbo Field Magnet showing how Coils are bunched together. 

indicated by the arrows. It is sufficient to investigate the distribution of temperature on one side, say the right side. Let the distance in centimetres of any point $\mathrm{P}$ from $\mathrm{M}$ be denoted by $x$. Let the crosssection of the conductor be $I$ sq. $\mathrm{cm}$., so that the volume of any element of length $d x$ is $d x$ cubic centimetre. Now as the resistance of copper is almost proportional to its absolute temperature, the resistance of a centimetre cube may be taken to be-

$$
\mathrm{R}=\frac{\mathrm{r} \cdot 6 \times 10^{-6} \times \mathrm{T}}{273}
$$

where $\mathrm{T}$ is its temperature in ${ }^{\circ} \mathrm{C}$. above the absolute zero.

If $I$ is the current density in amperes per square centimetre, the loss per cubic centimetre will be-

$$
\mathrm{I}^{2} \mathrm{R}=\mathrm{I}^{2} \times \frac{\mathrm{I}^{\cdot 6} 6 \times 1 \mathrm{O}^{-6} \times \mathrm{T}}{273} .
$$

The amount of heat passing through the centimetre of cross-section at the point $P$ will be the sum of all the heat produced between $M$ and $\mathrm{P}$ - that is to say-

$$
\mathrm{I}^{2} \times \frac{\mathrm{I}^{6} 6 \times \mathrm{IO}^{-6}}{273} \int_{0}^{x} \mathrm{~T} d x .
$$

Now the heat conductivity of copper is such that when there is a difference of temperature of $\mathrm{I}^{\circ} \mathrm{C}$. between opposite sides of a centimetre cube the flow of heat through the centimetre arrear is equivalent to the heat produced by 3 watts. Therefore three times the temperature gradient gives us the heat-flow per square centimetre in watts. As $x$ increases the temperature decreases, so that $\frac{d T}{d x}$ is negative. Thus we have-

$$
-3 \frac{d \mathrm{~T}}{d x}=\mathrm{I}^{2} \times \frac{\mathrm{I} \cdot 6 \times \mathrm{ro}^{-6}}{273} \int_{0}^{x} \mathrm{~T} d x .
$$

We may take as a solution-

$$
\mathrm{T}=\mathrm{T}_{\max } \cos p x .
$$

In cases which we work out in practice the angle $p x$ never assumes values which make $\cos p x$ negative, so that $\mathrm{T}$ is always positive. If $T$ were negative it would be below the absolute zero. The above solution would only be wholly true if the resistance of copper were negative below the absolute zero.

The distribution of temperature in a conductor such as we have supposed is therefore given by the top part of a cosine curve as shown in Fig. 9 .

VOL. 48. 
The value of $p$ is-

Therefore-

$$
\begin{aligned}
& \sqrt{\mathrm{I}^{2} \times \frac{\mathrm{I}^{6} 6 \times 10^{-6}}{3 \times 273}} \\
& p=4.43 \times 10^{-5} \times \mathrm{I} .
\end{aligned}
$$

where-

$$
\mathrm{T}_{x}=\mathrm{T}_{\text {max. }} \cos \left(4.43 \times 10^{-5} \times \mathrm{I} \times x\right) \text {, }
$$

I is the current density in amperes per square centimetre, $x$ is the distance from the hottest point in centimetres,

$\mathrm{T}_{x}$ is the absolute temperature at any point $x$, $\mathrm{T}_{\text {max. }}$ the absolute temperature at the hottest point.

An example will make this clearer. Suppose that we have a hotbed of conductors so bulky that we can assume that the centre con.

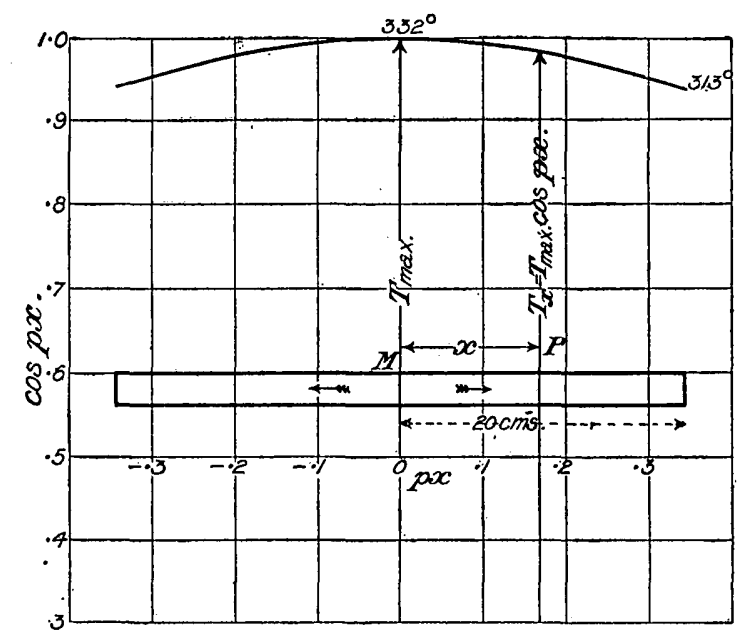

Fig. 9.-Temperature Gradient in a Conductor along which Generated Heat is flowing.

ductor parts with no heat laterally. All heat generated in it passes by conduction to points $20 \mathrm{~cm}$. away from the centre, which we will suppose are maintained at $40^{\circ} \mathrm{C}$. Each conductor is $\mathrm{O}^{\prime} \mathrm{r}$ sq. in. section, and carries a current of $25^{\circ}$ amperes. What is the temperature of the hottest point?

$$
\begin{aligned}
\mathrm{I} & =388 \text { amperes per square centimetre. } \\
\mathrm{T}_{x} & =(40+273)=3 \mathrm{I} 3 . \\
3 \mathrm{I} 3 & =\mathrm{T}_{\max .} \cos \left(4.43 \times \mathrm{IO}^{-5} \times 388 \times 20\right) . \\
3 \mathrm{I} 3 & =\mathrm{T}_{\max .} \cos 0^{\circ} 343=0^{\circ} 94 \mathrm{I} \mathrm{T}_{\max .} . \\
\mathrm{T}_{\max .} & =33^{2} .
\end{aligned}
$$

$33^{2}-273=59^{\circ} \mathrm{C}$. is the temperature of the hottest point. 
Now consider the case where part of the heat generated is radiated from the surface of the group of conductors, and part is conducted to the ends. In all cases which occur in practice there is a certain specified temperature on the outside of groups of coils which must not be exceeded. Assuming in the first instance that the temperature is reached, we can roughly estimate the number of watts per square centimetre which will be dissipated from the surface, having regard to the thickness of insulation and the amount of air circulation. Let $\mathrm{W}$ represent the total watts lost in the group of conductors, and $w$ the watts dissipated from the surface. Then $\mathrm{W}-w$ will be the heat watts conducted along the copper. The temperature rise of the hottest point will be lower than if no heat were lost laterally. Let us say that the temperature rise is the same as it would be if the current density were reduced from $I$ to $I_{x}$ and no heat were lost laterally.

Then-

$$
\frac{\mathrm{I}_{1}^{2}}{\mathrm{I}^{2}}=\frac{\mathrm{W}-w}{\mathrm{~W}}
$$

From the value of $I_{x}$ thus obtained we can as a first approximation find the temperature of the hottest point by the foregoing formula, and get a fair idea of the mean temperature of the whole cooling surface. We can then make a more accurate estimate of $w$, and if necessary recalculate $I_{x}$, and from it $T_{\max }$.

The experiments which we devised to check the above method of calculation were spoilt by an accident. They are being repeated.

\section{Cooling by Air.}

There are three main cases occurring in electrical machinery in which it is necessary to calculate the rate of convection of heat from a solid surface to the surrounding air.

I. We have the case of an armature or field magnet of approximately cylindrical shape revolving within the stationary part of the machine. (Cooling coefficient denoted by $h_{y}$.)

2. We have the case of a field coil against which a draught of air is blowing. (Cooling coefficient denoted by $h_{d \cdot}$ )

3. We have the case of the iron surface of a ventilating duct, through which the air is passing at a certain velocity. (Cooling coefficient denoted by $h_{v}$.)

The laws of cooling of the solid surface are different in the three cases. The first case (the cooling of the revolving cylinder) is very complicated. A formula for the close pre-determination of temperatures would have to take into account, not only the square inches per watt and the peripheral speed, but also the length of the air-gap, the temperature and shape of the surrounding objects, as well as of the air, the nature of the cooling surface, and the rate at which the air in the gap is changed by artificial ventilation. What are we to take as the velocity 
of the air, relatively to the cylinder, when some air moves with the cylinder, some clings to the stationary part, and all intermediate velocities are to be found somewhere in the air-gap?

For ordinary direct-current armatures surrounded by ordinary field magnets, with normal air-gaps, and with no more interchange of air than is naturally produced by the rotation of the armature, the formula given by Kapp-

$$
t^{\circ}=\frac{55^{\circ}}{\frac{\mathrm{O}}{\mathrm{W}}(\mathrm{I}+\mathrm{o} \cdot \mathrm{x} \nu)}
$$

gives good practical results. Here $\mathrm{O}$ is the area of the cylindrical surface in square centimetres, $\mathrm{W}$ the watts to be dissipated, $v$ the peripheral velocity in metres per second, and $t^{\circ}$ the ${ }^{\circ} \mathrm{C}$. rise above the surrounding air.

Other writers give different values of the numerator $55^{\circ}$, and change the value of the coefficient of $v$. Others change the index of the power of $v$. Here is a list-

Arnold-

$$
t^{\circ}=\frac{300}{\frac{\mathrm{O}}{\mathrm{W}}\left(\mathrm{I}+\mathrm{O}^{\circ} \mathrm{I} v\right)}
$$

Wilson-

$$
t^{\circ}=\frac{640}{\frac{\mathrm{O}}{\mathrm{W}}(\mathrm{I}+0.18 v)} .
$$

Hawkins and Wallis-

$$
t^{\circ}=\frac{4^{12}}{\frac{\mathrm{O}}{\mathrm{W}}\left(\mathrm{I}+0^{\prime} 086 v^{13}\right)} .
$$

Ludwig Ott-

$$
t^{\circ}=\frac{333}{\frac{\mathrm{O}}{\mathrm{W}}(\mathrm{I}+0 \cdot 107 v)}
$$

Hinlein-

$$
t^{\circ}=\frac{\mathrm{I}, 730}{\frac{\mathrm{O}}{\overline{\mathrm{W}}}\left(\mathrm{I}+0^{\circ} 78 \sqrt{v)}\right.} \quad\left\{\begin{array}{c}
\text { when } y \text { is between } \mathrm{x} \text { and } \\
\text { Io metres per second }
\end{array}\right.
$$

and-

$$
t^{\circ}=\frac{700}{\frac{\mathrm{O}}{\mathrm{W}}(\mathrm{I}+0.04 \mathrm{I} v)} \quad\left\{\begin{array}{l}
\text { when } v \text { is between ro and } \\
20 \text { metres per second. }
\end{array}\right.
$$

The reason for the difference of opinion that exists as to the index of the power of $v$ becomes apparent when we examine the results obtained by $\mathrm{E}$. Hinlein* as plotted in Fig. Io. For velocities between

* Zeitschrift des Vereines Deulscher Ingenienre, vol. 55, p. 730, I9I I. 
$\mathrm{x}$ and ro metres per second $h_{y}$ is almost proportional to $\left(\mathrm{I}+\mathrm{o}^{\prime} 78 \sqrt{v}\right)$, but as the velocity increases the curve straightens out so that, above ro metres per second, $h_{y}$ may be taken as proportional to $\left(\mathrm{I}+0^{\circ} \mathrm{O} 4 \mathrm{r} v\right)$. The small coefficient, $0.04 \mathrm{I}$ obtained by Hinlein seems to be due to the particular way his experiments were conducted.

For an ordinary armature surrounded by its field magnet the coefficient $O^{\prime} I$ scems to be about right. For the numerator the figure 550 seems to be rather high for iron-clad armatures. The figure 333 given by Dr. Ott seems to give good results for turbo-generators with forced ventilation.

When a cylinder revolves in air, the rate at which the air immediately in contact with it changes depends not only on the peripheral speed but on all sorts of accidental circumstances such as the shape of the stationary parts and the rate at which air is forced into the air-gap by the fanning action of other parts of the machine. A high relative velocity between rotor and stator is of service in causing the heat to pass easily from the heated surface to the air, but some further fanning action is necessary to remove the jacket of hot air away from the surface of the cylinder.

In a certain experiment described below the number of watts of heat-flow communicated to the air by a cylindrical surface of a stator of $2,960 \mathrm{sq}$. in. was II,700, so that we had-

or-

$$
\frac{\mathrm{Ir}, 700}{2,960}=3^{\prime} 95 \text { watts per square inch, }
$$

$$
=0.6 \mathrm{r} \text { watt per square centimetre. }
$$

The peripheral velocity of the surface of the rotor in this case was 92 metres per second. It was no doubt on account of the high peripheral velocity of the rotor that the cooling on the surface of the stator was so good. The law of cooling of the external surface of the rotor and of the internal surface of the stator will be somewhat similar. It is therefore of interest to apply the formula given by $\mathrm{Dr}$. Ott to the cooling of the surface of the stator. The mean temperature rise of the iron on the cylindrical face appears to have been about $40^{\circ} \mathrm{C}$. This is obtained from Fig. 22. The mean temperature of the air in the air-gap was $20^{\circ} 5$, leaving a difference of 19.5. Filling in these values in Ott's formula given above, we have-

$$
\begin{gathered}
19.5=\text { watts per square centimetre } \times \frac{333}{1+0.107 \times 9^{2}} \\
\text { watts per square centimetre }=0.635 .
\end{gathered}
$$

This agrees very closely with the actual figure $0.6 \mathrm{r}$ obtained.

No doubt the variation of the coefficients has arisen partly through an attempt being made to make the same formula cover the cooling of coils which fall under case 2, as well as the cooling of revolving 
cylinders. The cases being essentially different cannot be brought under the same law.

In the case of field coils, an increase in the velocity of the current of air not only increases the intimacy of contact between the air and the surface of the coil, but at the same time increases the quantity of air passing the coil in a given time. We therefore have the index of the power of $v$ greater than for the case of a revolving cylinder, the air surrounding which is not necessarily changed at a rate proportional to $\boldsymbol{v}$.

In cases $I$ and 2 there is a cooling of the surface by radiation, apart altogether from the passage of air, the formula should therefore give a value to $h$ when $v$ equals 0 .

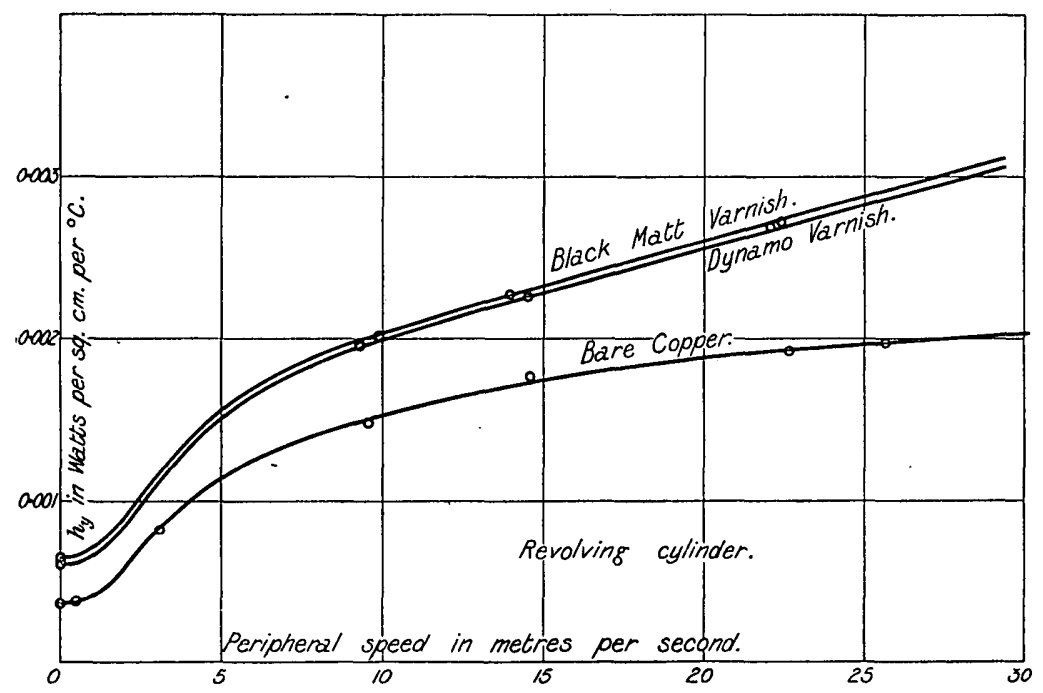

FIG. ro.-Hinlein's Curves for the Cooling of a Revolving Cylinder.

In case 3 , where two sides of a ventilating duct face one another, there is no dissipation of heat unless the air moves through the duct, and it will be seen from the experiments described below that the rate of cooling is approximately proportional to $v$.

For the purpose of determining the relation between the cooling coefficient $h_{d}$, in case 2 , and the velocity of the draught blowing on the sides of the coil, a number of experiments were made with the apparatus shown in Figs. 3 and 4. A certain number of watts were supplied by the heater inside the coil, and the temperature of the surface of the coil was ascertained by means of thermo-couples mounted in shallow niches in the surface, and protected from the draught by a very thin piece of insulation of a size not large enough to 
interfere with the uniform cooling of the coil. Tests were made with no breeze blowing and with breezes of various velocities. The results are plotted in Fig. II. In these tests the surface of the coil was made up of double cotton-covered wire 0.08 in. diameter. In some other tests a brass cylinder was used. In these the results were much more uniform as shown by the points on Fig. I2. It seems from these tests that the law connecting $h_{d}$ and $v$ is of the form $h_{d}=a\left(\mathrm{I}+b v^{2}\right)$, where $a$ and $b$ are constants depending and the kind

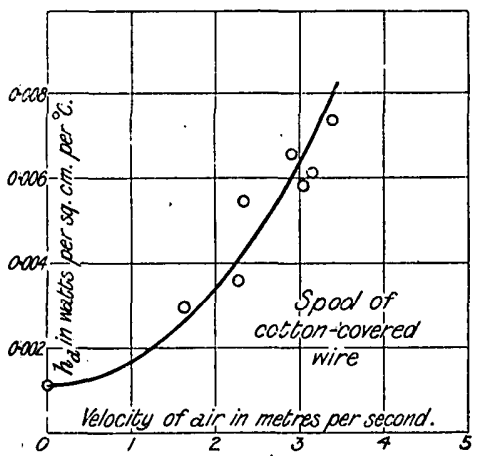

FIG. II.-Relation between $h_{d}$, the Watts per Square Centimetre per ${ }^{\circ} \mathrm{C}$., and Velocity of Air when Air blows upon a Cylindrical Coil as illustrated in Fig. 3.

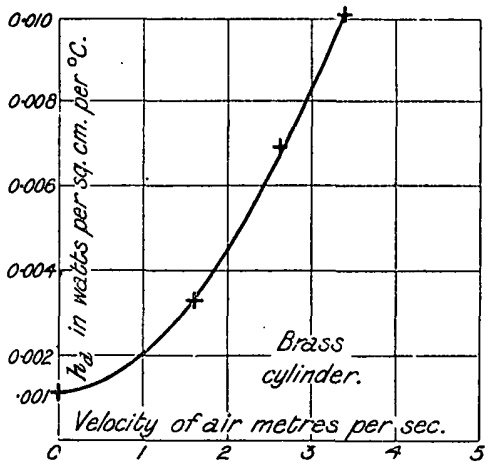

FIG, I2.--Relation between $h_{d}$, the Watts per Square Centimetre per - C., and Velocity of Air when Air blows upon a Cylinder of Tarnished Brass as indicated in Fig. 3.

of surface and the way the blast strikes the surface. For the brass cylinder with a draught on each side as indicated in Fig. 3, the law is-

$$
h_{d}=0.00 \mathrm{II}\left(\mathrm{I}+0.78 v^{2}\right) \text {. }
$$

In the case of cotton-covered wire the law is approximately-

$$
h_{d}=0.001 \mathrm{I}\left(\mathrm{I}+0.54 v^{2}\right) \text {. }
$$

In our experiments the draught did not exceed $700 \mathrm{ft}$. per minute, or 3.5 metres per second. It is possible that at higher velocities the law may change but the velocities investigated cover those generally obtaining in electrical machines.

The third case, the cooling of the sides of a ventilating duct, was investigated in some experiments on a turbo-generator described below. We will give the results here in Fig. 13, because it is of interest to put Figs. IO, II, I2, and I3 next to one another and observe the difference in the nature of the laws connecting $h$ and $v$.

In case 3 we know that $h_{v}$ must be zero when no air passes along the duct, and so far as our experiments go, $h_{v}$ seems to be almost pro- 
portional to $\nu$. The dotted line with the two circles on it was obtained by keeping all the conditions constant except that the velocity of the air was changed from 3.95 metres per second to 7.9 metres per second. The other points shown by crosses are from other experiments and calculated for other parts of the machine. Probably the black line may be taken to give the law of $h_{v}$ for the ventilating ducts for a turbo-generator.

\section{The Cooling of Wire-wound Colls.}

In predetermining the temperature rise of a wire-wound coil, we must first find the temperature rise of the external and internal surfaces of the coil. These will be the temperatures at which the coil can dissipate to the surrounding medium all the heat generated within it. In the

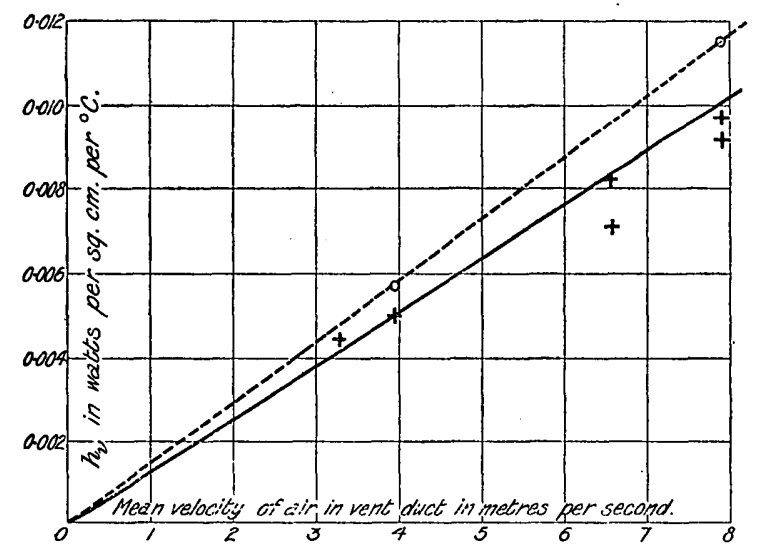

FIG. I3.-Relation between $h_{v}$, the Watts per Square Centimetre per ${ }^{\circ} \mathrm{C}$. (difference in Temperature between Iron and Air), and the Velocity of Air in the Ventilating Duct.

next place we must find the rise of temperature of the hottest part above the external surface by taking into account the heat conductivity of the layers of insulated wire and the watts per cubic centimetre generated within the coil.

Some designers make their shunt coils to be entirely air cooled. They provide such large air ducts between the coils and the poles that all heat passes to the air. Other designers make the coils a tight fit on the poles, and rely upon conduction of a large portion of the heat generated through the insulation to the body of the pole, whence it passes to the frame, or is dissipated from the pole-face. These two cases require rather different treatment.

Where the coil is entirely air cooled, some rough estimate should be made of the mean velocities of air passing over the external surface and along the ventilating ducts, and from these the specific cooling constants can be arrived at from Fig. II. Any estimate of this kind will, of 
course, be very rough indeed, and it is generally by experiments on similar coils, similarly mounted, that one must rely in determining the surface-cooling constants. Still, Fig. II is of service in indicating the direction in which we may hope to obtain an improvement in the cooling conditions, perhaps without much increase in the cost of construction.

Where the coil is a fairly tight fit on the pole, we should take account of the thickness and nature of the insulation and calculate the number of watts which will be conducted to the pole for a given temperature difference in the manner indicated in the example given in copjunction with Fig. 5. The rate at which the heat will be conducted along the pole is sometimes of importance. For this purpose it is useful to remember that a temperature gradient of $\mathrm{I}^{\circ} \mathrm{C}$. per centimetre in wrought iron causes heat to flow at the rate of 0.7 watt per square centimetre. Account must also be taken of the means that are available for dissipating the heat from the pole itself. For instance, some rotating field generators are provided with vents in the poles, and the laws for their cooling will be somewhat similar to the laws laid down for armatures.

By taking account of these matters and knowing the total watts lost in any particular coil it is not difficult to apportion the loss between the outside, the inside, and the ends of the coil, and come to a fairly accurate estimate of the temperature which the outside surfaces must attain in order to get rid of the heat.

The next question that arises is: How much higher is the temperature inside the coil ?

A great deal of most valuable data on the heating of shunt coils is given by Mr. E. H. Rayner in his "Report on Temperature Experiments at the National Physical Laboratory." * A study of the curves and figures given will show that the distribution of temperature inside a wire-wound coil follows definite laws. If we are given full particulars of the size of wire, the thickness of the insulation, the space factor, the number of turnsı and layers, the exciting current, and so on, we should be able to predetermine with a sufficient degree of accuracy the temperature of the hottest part of the coil.

The problem is somewhat analogous to the case already considered where the heat is conducted along copper conductors, but in this case the heat is conducted across one layer of conductors to another. The law of distribution of temperature takes the same general form-

$$
\mathrm{T}_{x}=\mathrm{T}_{\max .} \cos p_{\mathrm{r}} x,
$$

where $T_{\max }$ is the temperature of the hottest point measured from the absolute zero, and $\mathrm{T}_{x}$ is the temperature of any point distant $x$ centimetres from the hottest point along a line drawn in the direction of the flow of heat at right angles to the cooling surface. The value of $p_{\mathrm{t}} \cdot x$ in practice is such that $\cos p_{\mathrm{r}} x$ never assumes negative values.

* Fournal of the Institution of Electrical Enginecrs, vol. 34, p. 6r3, 1905; and G. A. Lister, ibid., vol. 38, p. 399, I907. 
If we examine the various curves given by Mr. Rayner we shall see* that they are all part of cosine curves except in those cases where there is a discontinuity in the coil.

Take, for instance, Test No. 2 B. Add $273^{\circ} \mathrm{C}$. to the ordinates of the transverse section curve on page 639 (vol. 34), and we obtain a curve like that given in Fig. I4. The law of this çurve is-

$$
\mathrm{T}_{x}=389 \cos (0.0915 x) \text {. }
$$

If the coefficient $\left(p_{1}\right)$ of $x$ is known, and the distance from the hottest part is known, then we can calculate the amount that the temperature of the hottest part exceeds that of the surface. For instance, with the above law, if on the surface of the winding the temperature is $90^{\circ} \mathrm{C}$. $\left(363^{\circ}\right.$ absolute) and the hottest point is $4 \mathrm{~cm}$. from the surface, then-

$$
\begin{aligned}
3^{6} 3 & =\mathrm{T}_{\max .} \cos 0.0915 \times 4 \\
\mathrm{~T}_{\max .} & =3^{8} 9 .
\end{aligned}
$$

The value of $p_{\mathrm{r}}$ depends mainly on four factors :-

I. The current density in the copper.

2. The nature of the insulation and the thickness per centimetre depth of coil.

3. The space factor of the winding.

4. The ratio of the length of the bobbin to the depth of the winding.

In what follows we shall employ the following symbols:-

$l=$ length of bobbin in centimetres.

$d=$ depth of winding in centimetres.

$\mathrm{C}_{d}=$ current density in amperes per square centimetre.

$\mathrm{C}_{x}=\sqrt{\frac{l}{l+d}} \mathrm{C}_{d}$.

$\sigma=$ copper space factor.

$i_{n}=$ thickness of insulation per centimetre of depth of winding.

$k_{h}=$ heat conductivity of insulation in watts per square centimetre per ${ }^{\circ} \mathrm{C}$. per centimetre of path.

* It is not possible to predetermine the value of $p_{\mathrm{I}}$ in all the cases given by $\mathrm{Mr}$. Rayner because full particulars are not given of the thickness of the cotton coverings, but in several cases where we may assume the cotton covering is normal and the wires properly packed, the results agree closely, with the values of ' $p$ found by the authors' experiments; for instance in the case of coil No. 2 we have-

$$
p_{\mathrm{r}}=\mathrm{I} 27 \sqrt{\frac{0.63 \times 1.6 \times 10^{-6} \times 0.136}{0.00095 \times 273}}=0.0915 .
$$

The figures 127 amperes per square centimetre is obtained from the value $15 \mathrm{I}$ given in $\mathrm{Mr}$. Rayner's table by the formula for $\mathrm{C}^{x}$ given later in this paper. Length of coil $=7$ in., breadth $=3$ in. ; $7+3=10$.

$$
\sqrt{\frac{7}{10}}=0.84 ; \text { I } 51 \times 0.84=127 \text { : }
$$


Then-

$$
p_{1}=\mathrm{C}_{x} \sqrt{\frac{\mathrm{r}^{6} 6 \times \mathrm{IO}^{-6} \times \sigma \times i_{n}}{k_{h} \times 273}}
$$

In order to ascertain the values of $k_{h}$ for round and for square wire, treated and untreated, the authors made direct experiments on the heat conductivity of cotton-covered wire windings by means of the apparatus shown in Fig. 4.

Experiments were made with two sizes of wire 0.032 in. diamcter and $0^{\circ} I_{4}$ in. diameter. No current was passed through the wire. The heat was generated inside the copper tube (see Fig. 2), upon which the coil was wound and the temperature difference between two points (a known number of layers apart) ascertained by thermo-couples.

The figures given for the value of $k_{h}$ in Table III. allow a certain margin for variations in the construction of the coil which, so far as our

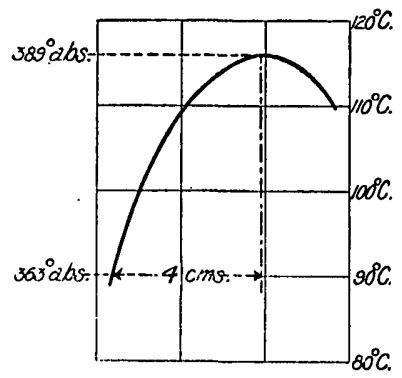

FIG. I4.-Curve No. 2 B from Mr. Rayner's Results showing the Law with Temperatures expressed in ${ }^{\circ} \mathrm{C}$. above the Absolute Zero. $T_{x}=389 \cos \left(0.09 I_{5} x\right)$.

tests went, were sufficient for tightly wound coils. For instance, the lowest value obtained for 0.032 in. round wire double cotton-covered electro-enamelled was 0.00065 , and the highest value for $0.11_{4}$ in. wire was $0^{\circ} 0009$. It is possible that the margin should be made wider. For loosely wcund coils it will be very wide. We assume that $k_{h}$ is independent of the thickness of the insulation on the wire. The thickness of the insulation of the wire is taken into account in the formula in the quantity $i_{n}$, which is obtained by multiplying the number of layers per centimetre with the double thickness of cotton covering on each wire.

Table III. gives the values of $k_{h}$.

\section{Heat Paths through the Ventilating Ducts.}

After we have provided sufficiently well for the conduction of the heat through the insulation either to the air or to the iron surrounding it, the next question is how to provide sufficient cooling surface so that 


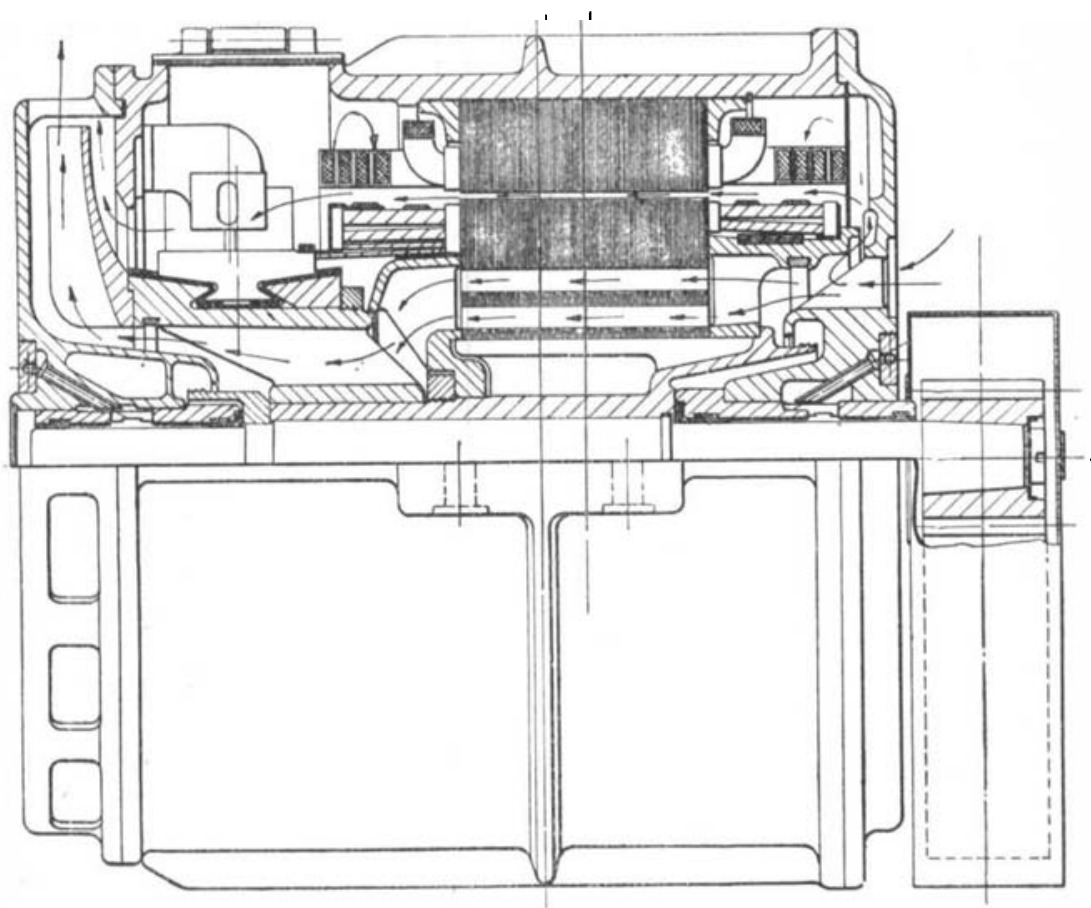

FIG. 15.-Railway Motor with Definite Scheme of Ventilation.

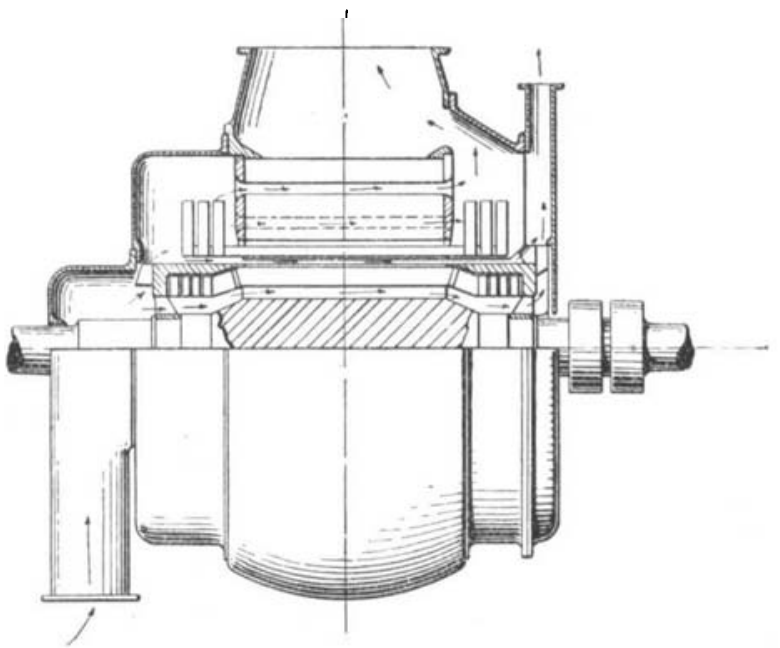

FIG. 16.--Scheme of Ventilation of Turbo-generator by means of Axial Holes; Air passing from one end of Machine to other. (Messrs. Siemens Bros.) 
the heat may be communicated to the air and carried away by it. There are really two matters involved; one is the provision of

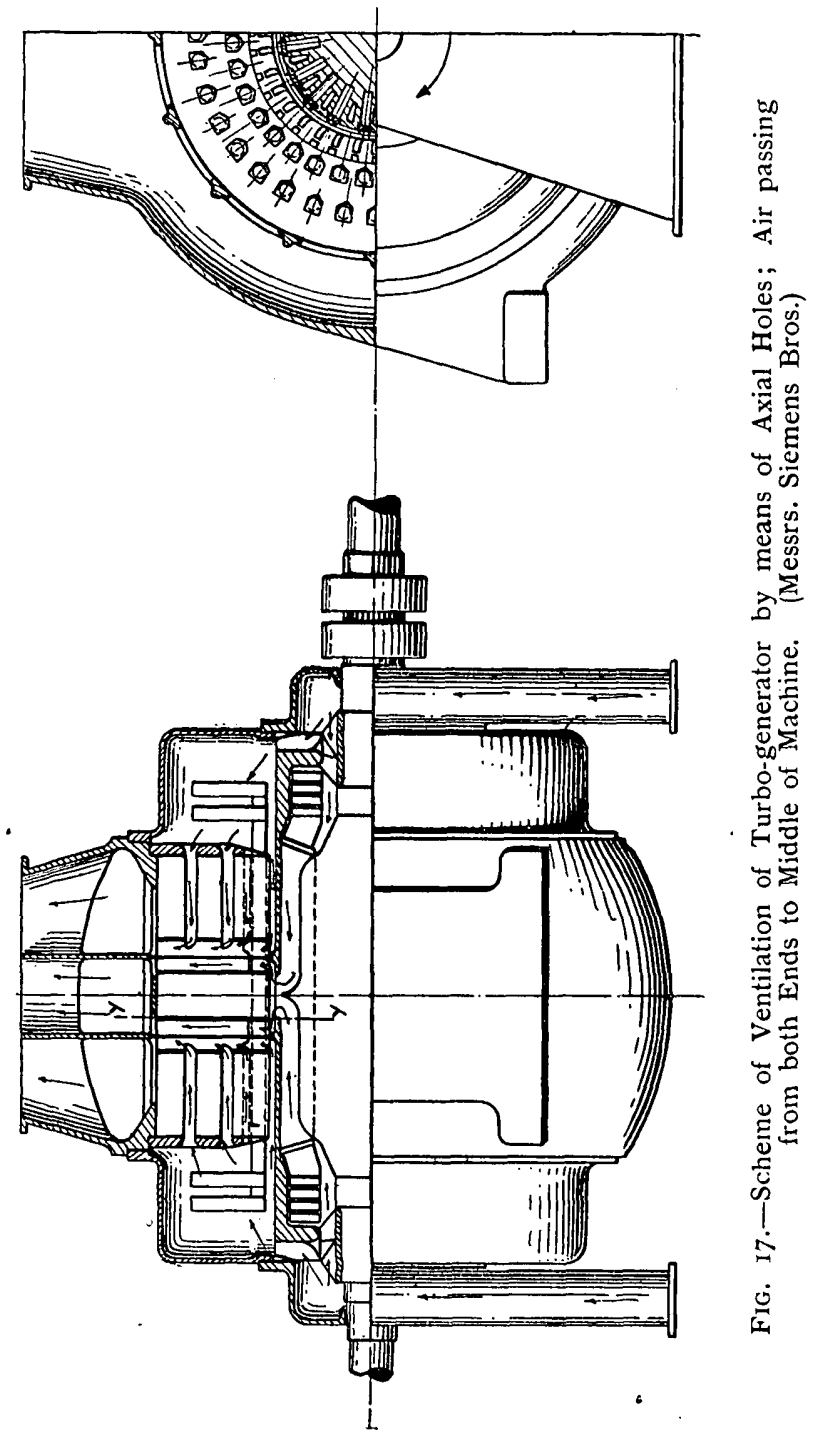

sufficient air to carry away the heat produced, and the other is the provision of cooling surface exposed in such a way as to heat up the air which passes through the machine. 
We know that I cub. $\mathrm{ft}$. of air per second $(60 \mathrm{cub}$. $\mathrm{ft}$. of air per minute), if raised in temperature $27^{\circ} \mathrm{C}$., will carry away $\mathrm{I}$ k.w. As a good deal of air sometimes passes through a machine without being raised much in temperature, it is usual to allow roo cub. $\mathrm{ft}$. of air per minute for each kilowatt loss.

As or how this cooling surface is to be provided is a question upon which there has been a good deal of difference of opinion amongst designers. In the open type of machine where the paths for the air are not very definitely prescribed, and where the quantity of air passing is usually unknown, only the very roughest empirical rules can be used for determining the temperature rise. Where, however, definite paths for the air are provided in the machine as in the motor illustrated in Fig. 15, and where the quantity of air passing is known, the cooling effectiveness of the surfaces can be approximately calculated.

In the cooling of large machines, such as turbo-generators, there are two general methods of providing paths for the air. According to one method, which is illustrated in Figs. 16 and 17 , the air is passed through axial holes both in the rotor and in the stator, and it is the internal surface of these axial holes which mainly constitutes the surface exposed. Sometimes the air is passed from both sides of the machine towards the middle, as in Fig. 16 , and in other cases the air is passed from one end of the machine to the other as in Figs. 15 and 17 .

According to the second method illustrated in Fig. 18, the air is passed through a spider or through axial holes in the rotor, and thrown out through radial ducts in the rotor to radial ducts in the stator.

The first method has been commended on account of the fact that the iron punchings, whose conduction is better along the laminations than across the laminations, can convey the heat more easily to the air than where the ducts are of the radial type parallel to the plane of lamination. How far this consideration is of importance will be considered after we have described the experiments carried out on a machine of the type depicted in Fig. I8. Another advantage of axial ducts is that they provide a more bountiful supply of air to the centre of the machine than is possible in a long machine of the type illustrated in Fig. 18.

The object of the experiments was to determine exactly how the air received its heat as it passed through a turbo-generator and to determine the value of $h_{v}$ (the watts per square centimetre per ${ }^{\circ} \mathrm{C}$. difference of temperature between surface and air). At the same time it was sought to determine how far the cooling of the iron was hindered by the poorer conductivity of the punchings across the laminæe than along the laminæe.

As the value of $h_{v}$ is dependent upon the $v$, and as it is the velocity of the air in intimate contact with the surface that is of chief importance, we may gather that for a given quantity of air passed through the machine narrow ducts will be more effective than wide holes. The ducts, however, must not be too narrow or they will be liable to be stopped 


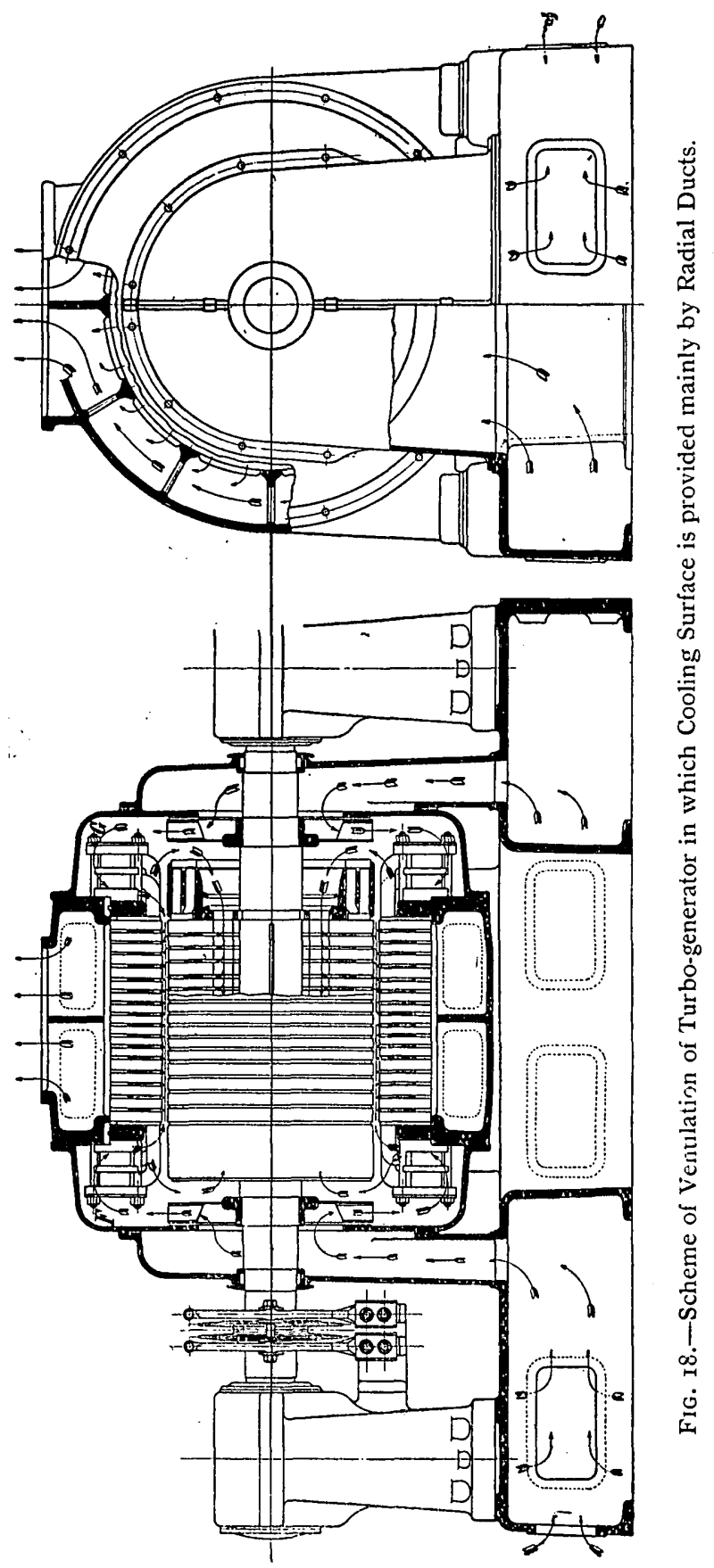




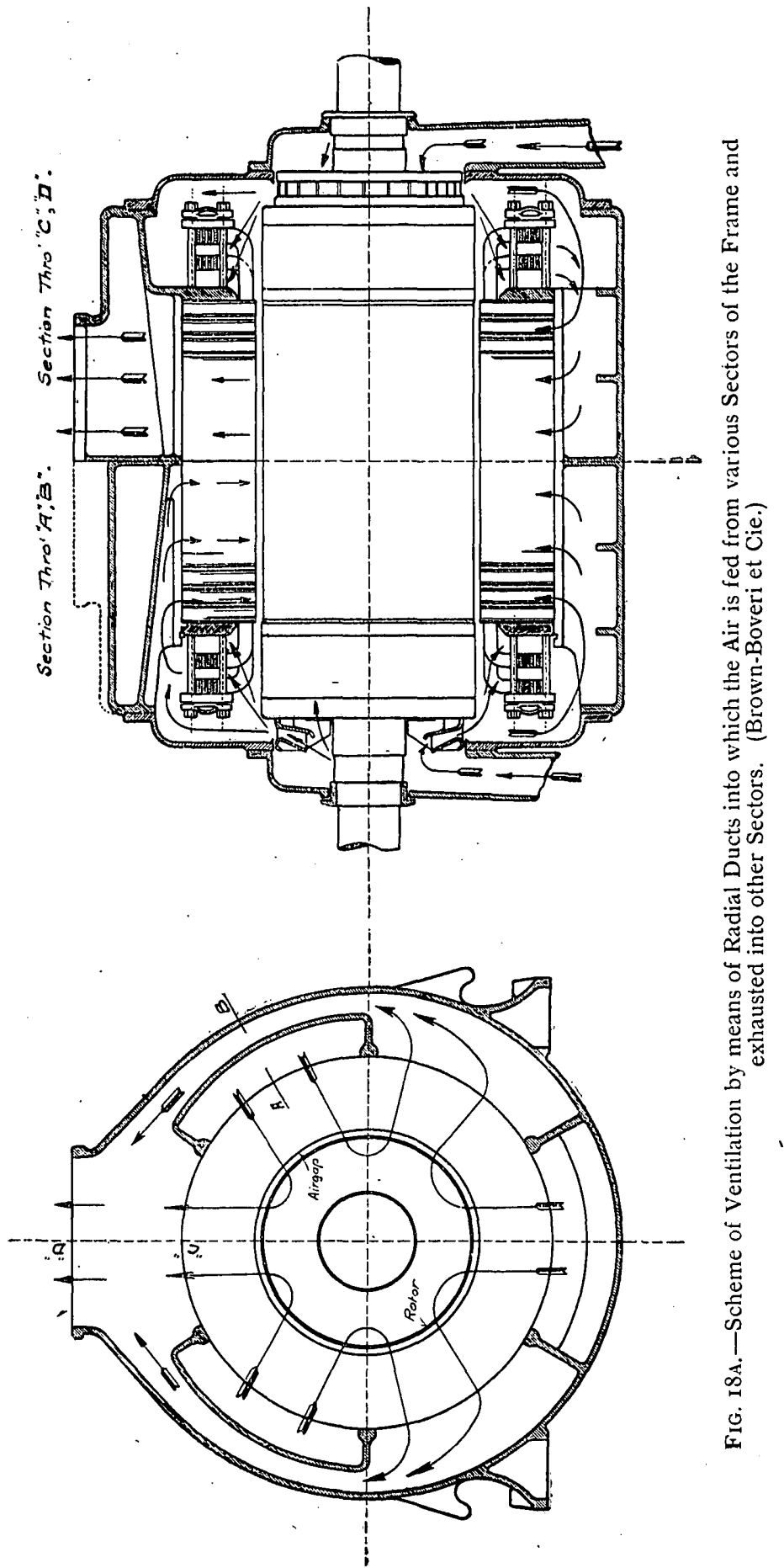

VOL. 48. 
up by the accumulation of dirt. Holes if too wide allow the air to pass without coming in close contact with the iron. It has been found that ventilating ducts from $\mathrm{O}_{3}$ in. to $\mathrm{O}_{4} 4$ in. wide having smooth iron walls will keep clean for a great number of years if the velocity of air passing through them is sufficiently great. A velocity of from 5 to ro metres per second is sufficient to prevent the accumulation of dust in the absence of oil spray. If any oil is allowed to enter with the air the accumulation of dirt will be facilitated. It has been found that round axial ventilating holes of 2 in. or 3 in. in diameter whose walls are formed from the rough punchings accumulate the dirt very rapidly; this is particularly so with the holes in rotors where the centrifugal

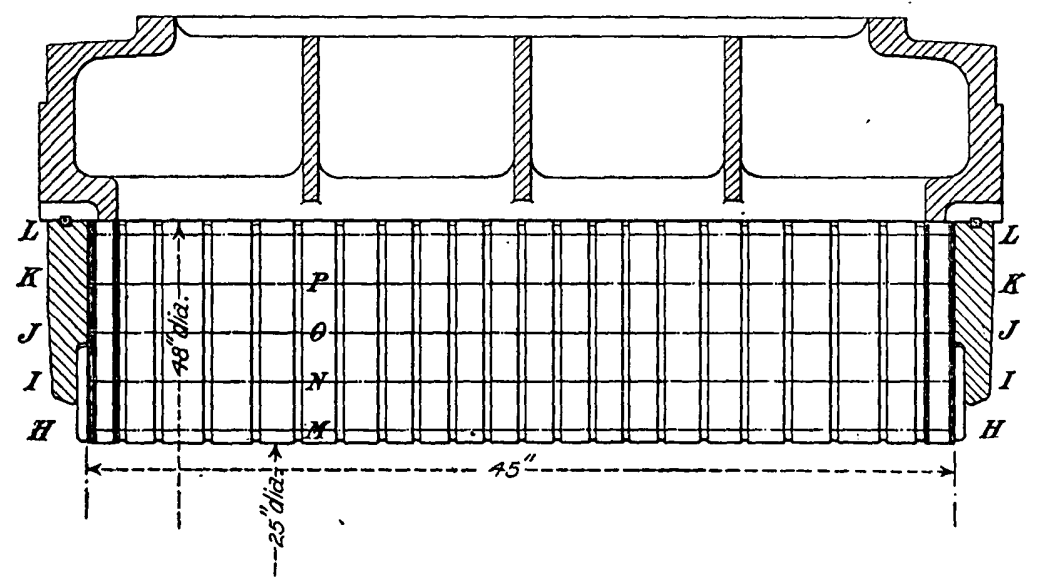

FIG. I9.-Showing Depths H, I, J, K; and L, to which Thermo-couples were inserted into Vent Ducts.

force can press particles of dust together on the internal surface of the hole furthest from the centre.

In cases where one cannot get rid of all the heat from the cylindrical surface of the armature, and where it is therefore necessary to provide further cooling surface, the radial ventilating duct of the type illustrated in Fig. I8 is very effective for the reasons stated above. It enables an exceedingly large. surface to be provided without unduly increasing the cost of the machine. It will be seen from the experiments made on the 1,875 -k.v.a. generator, as described below, that out of a total iron loss of $43^{\circ} 5 \mathrm{k} . \mathrm{w}$. II $7 \mathrm{k}$.w. was conveyed to the air by the cylindrical face of the armature, leaving $3 \mathrm{r} \cdot 8 \mathrm{k} . \mathrm{w}$. to be carried away from ventilating ducts and from other exposed surfaces. It is calculated that $23 \mathrm{k}$.w. of this was communicated to the air by the surface of the ducts and for this no less than $450,000 \mathrm{sq} . \mathrm{cm}$. of cooling surface were required when the difference of temperature between iron and air was $9^{\circ}$. The difficulty of getting a sufficient quantity of air through a 
very long machine with a small air-gap can be met by adopting the scheme of ventilation illustrated in Fig. 18A. Here certain channels are provided in the frame from which the air is forced inwards down the ducts to the air-gap and the rotor. Staggered with these channels are others which receive the air thrown outwards from the intervening sectors.

\section{Tests on a i,875-K.v.A. Generator.}

Tests were carried out on a totally enclosed turbo-generator of $\mathrm{I}, 875$-k.v.a. capacity, ventilated in the manner shown in Fig. 18 by means of fans at each end.

In certain parts of the machine ordinarily inaccessible to thermometers, thermo-couples were placed while the machine was in course of construction. Thus in the centre of the packet of punchings lying between the ventilating ducts Nos. 5 and 6 (see Fig. I9) thermocouples were placed at the points $\mathrm{M}, \mathrm{N}, \mathrm{O}$, and $\mathrm{P}$. Then in the ventilating ducts at the lower part of the machine couples were exposed to the full blast of air so that readings could be taken of the temperature of the air in the ducts at that part to compare with the temperature of the air in the same ducts at the top of the machine.

The generator was run at no load and the iron loss, friction and windage measured in the ordinary way by measuring the power supplied to the driving motor. The rotor was mounted in its own bearings and coupled to a driving pulley mounted on independent bearings. The pulley was driven by a direct-current motor at 3,000 revs. per minute. The power taken to drive the pulley alone with the full tension on the belt was found to be $13 \mathrm{k} . \mathrm{w}$. The sum of the friction of the generator bearings and the windage was found by deducting $13 \mathrm{k} . \mathrm{w}$. from the whole combination. With full aperture allowed to the fan, the sum of the friction and windage amounted to $46 \mathrm{k}$.w. In order to ascertain the amount of power lost in the bearings measurements were made of the quantity of oil supplied to each bearing per minute and the rise in temperature of the oil. A rough estimate was also made of the quantity of heat lost by the bearings by radiation and convection. It was found that the heat carried away by the oil in one bearing was equivalent to $7.9 \mathrm{k} . \mathrm{w}$. , and from the other $6{ }^{7}$ k.w. The radiation and convection losses of the two bearings together was less than I k.w., so the total bearing losses were about $156 \mathrm{k} . \mathrm{w}$. This left $46-15^{\circ} 6=30^{\circ} 4 \mathrm{k} . \mathrm{w}$. for the windage with full aperture, giving $8,800 \mathrm{cub}$. ft. of air per minute at $50^{\circ} \mathrm{C}$. With a reduced aperture giving $4,400 \mathrm{cub}$. $\mathrm{ft}$. of air per minute the windage loss was $22 \cdot 8$.

The amount of air passed through the machine per minute was measured in two different ways : (I) An anemometer was used to find the mean velocity of air at the exit in feet per minute, and this multiplied by the area of the exit in square feet gave roughly the cubic feet per minute. (2) The total rise in temperature of the air in passing through the machine was measured, and from the known losses causing 
the heating the flow of air could be calculated. The first method was not as accurate as the second. It gave on the average an air velocity from 5 to 7 per cent. too high. We have therefore adopted the figures given by the second method. These are probably right within 5 per cent. It must be remembered that what we are really concerned with is the weight of air passed through the machine per minute. The volume of the air changes with the temperature quite appreciably. Thus at $20^{\circ} \mathrm{C}$, 750 lbs. of air have a volume of $10,000 \mathrm{cub}$. $\mathrm{ft}$., while at $60^{\circ} \mathrm{C}$. the volume is II,400 cub. $\mathrm{ft}$. There were three tests, which we distinguish by the letters $\mathrm{A}, \mathrm{B}$, and $\mathrm{C}$.

In test $\mathrm{A}$ the air supply was cut down to about half its normal fow. The field magnet was excited with I 33 amperes (about 30 per cent. more than the no-load field current.) The resulting iron loss was $43^{\circ} 5^{-k}$.w. and the $I^{2} R$ loss in the field magnet was $8.5 \mathrm{k} . \mathrm{w}$. Thus the total losses going to warm up the air were-

\begin{tabular}{|c|c|c|c|c|c|c|}
\hline Windage $\ldots$ & $\cdots$ & $\cdots$ & $\cdots$ & $\cdots$ & $\cdots$ & $\begin{array}{c}\text { Kilowalts. } \\
22 \cdot 8\end{array}$ \\
\hline Excitation ... & $\ldots$ & $\ldots$ & $\ldots$ & ... & $\ldots$ & $8 \cdot 5$ \\
\hline Iron loss $\ldots$ & $\cdots$ & $\cdots$ & $\cdots$ & ... & $\cdots$ & 43.5 \\
\hline & & otal & $\ldots$ & $\ldots$ & $\ldots$ & $74^{\cdot 8}$ \\
\hline
\end{tabular}

After running 4 hours the temperature of all the parts of the machine rose within half degree of their final temperature. The air entered the machine at an average temperature of $2 \mathrm{I}^{\circ} 7^{\circ} \mathrm{C}$., and was expelled at an average temperature of $53^{\circ} 2^{\circ} \mathrm{C}$., giving a temperature rise of $3 \mathrm{I}^{\circ} 5^{\circ}$. The heated air did not represent the whole of the heat produced. The cast iron frame presented a cooling surface of Io,900 sq. in. and had a mean temperature over the air of $28^{\circ} \mathrm{C}$., so that it would radiate * in almost still air about-

$$
\text { I0,900 } \times 0.008 \times 28=2.44 \text { k.w. }
$$

The cast-iron blocks upon which the frame rested would carry away not more than $\mathrm{I}^{\cdot} 5 \mathrm{k}$.w. Let us say that $4 \mathrm{k}$.w. was lost by the frame. This is such a small fraction of the whole that we need not estimate it very accurately. Then we have $74.8-4=70.8 \mathrm{k}$.w. carried away by the air. Now I k.w. is equal to 240 calories per second, so we have-

$$
70 \cdot 8 \times 240=17,000 \text { calories per second. }
$$

\footnotetext{
* It is of interest to note what a small fraction of the total losses on a large turbogenerator are dissipated by external radiation; in this case about $5 \frac{1}{\frac{1}{2}}$ per cent. In the case of a medium-speed generator of $5 \mathrm{k} . \mathrm{w}$, about 50 per cent. of the losses can be accounted for in external radiation. Radiation is used here in its commonly accepted inaccurate sense and includes convection to nearly still air. The true radiation by heat waves is rather less thar half of these figures, and may be calculated approximately from the formula :-

$\mathrm{H}$ in gram calories per sec. $\doteq$ surface in sq. cm. of equivalent sphere $\times \sigma \times\left(\mathrm{T}_{1}{ }^{4}-\mathrm{T}_{2}{ }^{4}\right)$ where $\sigma=0.6 \times 10^{-12}$ for a dark painted generator and $T_{1}=$ temperature of generator in ${ }^{\circ} \mathrm{C}$. above absolute zero. $\mathbf{T}_{2}=$ temperature of surrounding objects above absolute zero,
} 
Taking the specific heat of air at 0.2375 we have-

$$
\frac{\mathrm{I} 7,000}{0^{\circ} 2375} \times \frac{\mathrm{I}}{3^{\cdot} \cdot 5} \times \frac{\mathrm{I}}{453} \times \frac{60}{\mathrm{I}}=300 \mathrm{lbs} . \text { of air per minute, }
$$

or $4,400 \mathrm{cub}$. ft. of air at $53^{\circ} \mathrm{C}$. The anemometer measured on the average 4,800 cub. $\mathrm{ft}$. of air per minute. This reading must be too high, because 4,800 cub. $\mathrm{ft}$. of air per minute raised in temperature $3^{\circ} 5^{\circ}$ represents more power than was actually supplied to the machine, so we will take 4,400 cub. $\mathrm{ft}$. as about right.

It is interesting now to see exactly how the air was heated up as it passed through the machine.

The temperature of the air in the various ventilating ducts and in the air-gap was measured by a pair of thermo-couples, mounted on a long wooden rod, which could be moved about in the ducts while the machine was running. Two couples of equal resistance connected in parallel were used, one on each side of the rod, so that if there were any difference between the temperature of the air on one side of the duct and the other, the reading obtained gave the average value. The couples were of such a very thin wire (o.or in. diameter) and were mounted in such a way that when exposed to a breeze they assumed the temperature of the air almost immediately. It was therefore possible to take very rapidly a large number of readings of the temperatures at different depths in each air-duct, and to plot curves such as those given in Fig. 20. The lines marked $\mathrm{H}, \mathrm{I}, \mathrm{J}, \mathrm{K}$, and $\mathrm{L}$ are drawn through the points which give the readings of temperature rise at different depths in the ventilating ducts as indicated by the dotted lines in Fig. I9 bearing the corresponding letters. The hole at the top of the frame at which the air was expelled measured $36 \times 20$ in., and it was only over this area that it was possible to insert the wooden rod carrying the thermo-couples. In some parts within reach of this hole a flexible strip of press-spahn with a thermo-couple attached was used to take check readings, and the couples placed in the ducts in the lower part of the machine (that is to say, below the rotor) were used as a further check. These lower couples gave readings $2^{\circ}$ or $3^{\circ}$ higher than couples placed in the same ducts in corresponding positions at the top of the machine. This was possibly on account of the slightly lower velocity of the air thrown downwards, there being a certain amount of back pressure produced by the resistance of the flow of air through the annular space in the frame. As far as could be ascertained by a number of check readings taken over the field, available from the exit hole at the top, the chart in Fig. 20 represents fairly well the distribution of temperature in the ducts in the top half of the machine, and if similar charts had been taken in radial planes at various angles all round the machine, the chart would have been very similar, but all the temperatures would have been gradually raised about $3^{\circ}$ as we approached the planes lying below the rotor.

Temperatures were at the same time taken of the air admitted, 
of the air in the end bells, in the gap, in the yoke, and at eight different points distributed over the exit.

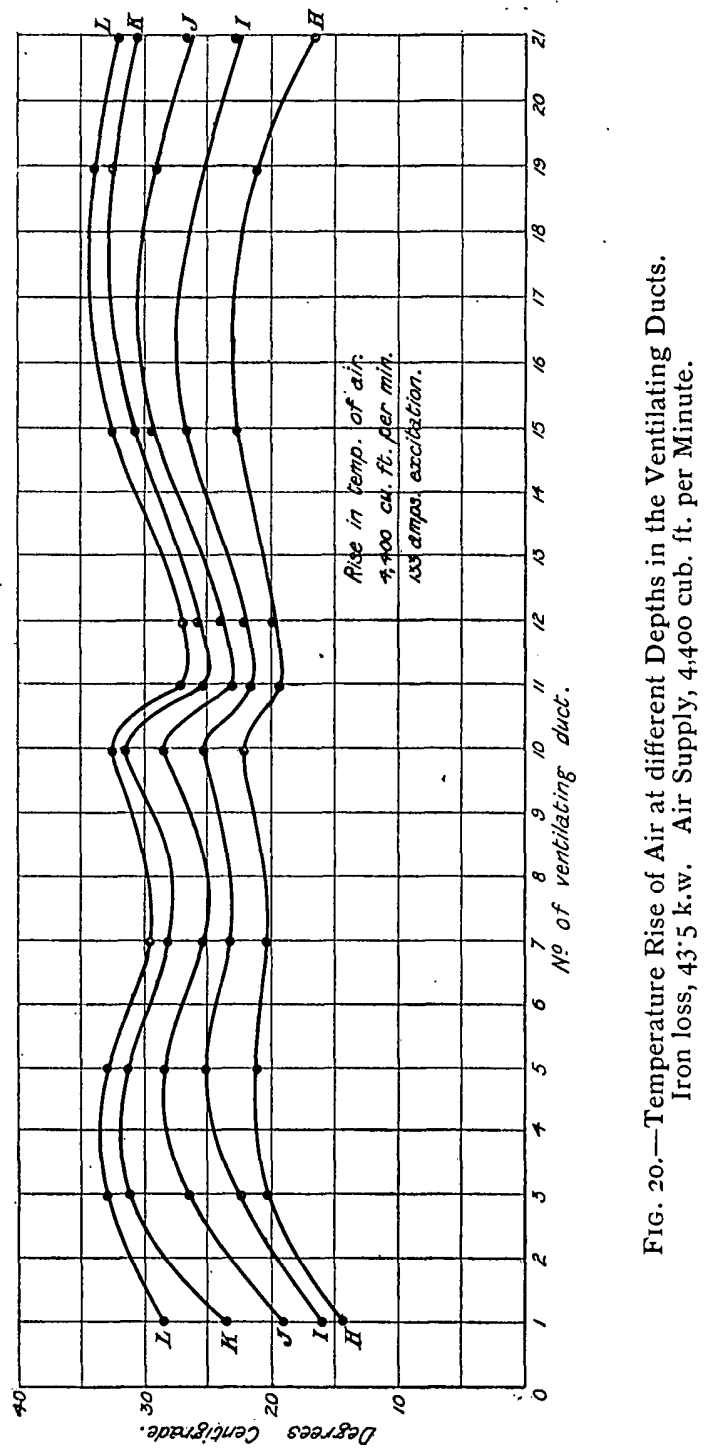

The average temperature of the air drawn into the machine was $2 \mathrm{I}^{\circ} 7^{\circ} \mathrm{C}$. It will be convenient to speak of the temperature rise over 
this initial figure, rather than of the actual temperature of the air. In the end bell at the points $\mathrm{F}$ and $\mathrm{G}$ the temperature had risen $9^{\circ} 8^{\circ} \mathrm{C}$. and $10 \cdot 2^{\circ} \mathrm{C}$. respectively. This rise was due partly to the work done to the

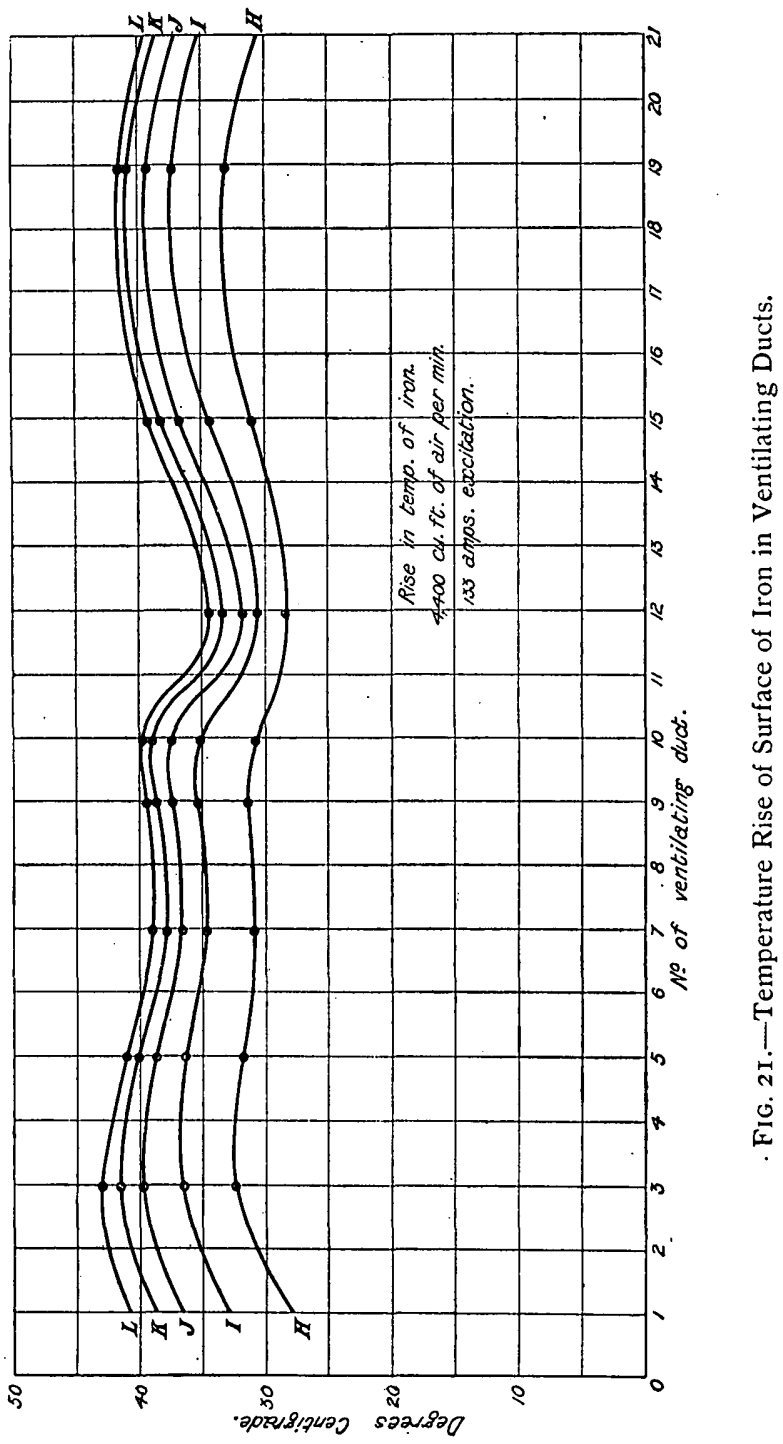

air due to the centrifugal blowers, partly windage and $I^{2} R$ losses from the end bells of the rotor, and partly from heat radiated from end plates of the machine. The lowest temperature recorded in the air-gap was 
at the entrance to the first ventilating duct. Here the rise was $14^{\circ} \mathrm{C}$. As we passed from the first vent duct to the centre of the machine the temperature was higher, but the increase followed an irregular law as indicated by the wavy line marked position $\mathrm{H}$ in Fig. 20. The curious dip in the curve in the centre of the machine which is also seen in the curves of temperature rise in the iron in Fig. 21 , only occurred when the air supply was throttled. It does not occur in Figs. 22, 23, 24 and 25. The throttling of the air supply reduced the pressure in the endbells from 4.25 in. of water for full aperture to 0.75 in. of water. Thus the blast along the air-gap must have been very much reduced, while the blowing action of the vent ducts on the rotor would have taken a more important part in the scheme of ventilation than when the full blast was in operation. Owing to the meeting of the two opposing currents of air in the axial holes in the rotor, there is a tendency for the pressure of air from the rotor to be greatest in the middle, and this increased pressure probably gave a supply of rather cooler air near the. centre of the machine.

The velocity of air at the exits of the different vent ducts, though not perfectly constant as one passed:from duct to duct, was only very slightly greater in the centre of the machine than at the ends. It is therefore sufficient for our purpose to take the mean temperature rise of the air entering the ducts as derived from curve $\mathrm{H}$ at $20^{\circ} 5^{\circ} \mathrm{C}$.

Let us now calculate the number of kilowatts, $x$, required to heat up the air to $20^{\circ} 5^{\circ} \mathrm{C}$. We have, from our previous calculations-

$$
\begin{aligned}
\frac{x}{70^{\circ} 8} & =\frac{20^{\circ} 5}{3 I^{\circ} 5} \\
x & =46 \text { k.w. }
\end{aligned}
$$

Now the windage only amounted to $22.8 \mathrm{k} . \mathrm{w}$. and the $\mathrm{I}^{2} \mathrm{R}$ in the field to 8.5 , so that we have $14.7 \mathrm{k} . \mathrm{w}$. in addition which must have been supplied by the iron loss, and communicated to the air mainly on the cylindrical face of the armature. A small amount-probably about 3 k.w.*-would be supplied to the air from the end plates of the armature. Deducting this, we have about $\mathrm{II}^{\prime} 7 \mathrm{k}$.w. conveyed to the air by the cylindrical face of the armature. As we have seen above, we are able from this data to calculate the specific rate of cooling per square inch of armature face.

As the air passes along the vent ducts the temperature rises; in some ducts the air received as much as $11^{\circ} 5^{\circ}$ further rise in temperature, in others not more than $8^{\circ}$ rise, the mean being about $10^{\circ} 2^{\circ}$ rise. If $y$ is the power expended in heating up the air 10 $2^{\circ}$, we have-

$$
\begin{aligned}
\frac{y}{70^{\circ} 8} & =\frac{\mathrm{IO}^{\circ} 2}{3 \mathrm{I}^{\circ} 5} \\
y & =23 \mathrm{k.w} .
\end{aligned}
$$

\footnotetext{
* That this amount is small can easily be seen when we come to calculate the amount of heat given to the air in one ventilating duct:
} 
Now the air passes into the annular space in the frame and picks up a little more heat from the punchings. Part of this extra heat is communicated to the frame and is radiated from the outside, and part

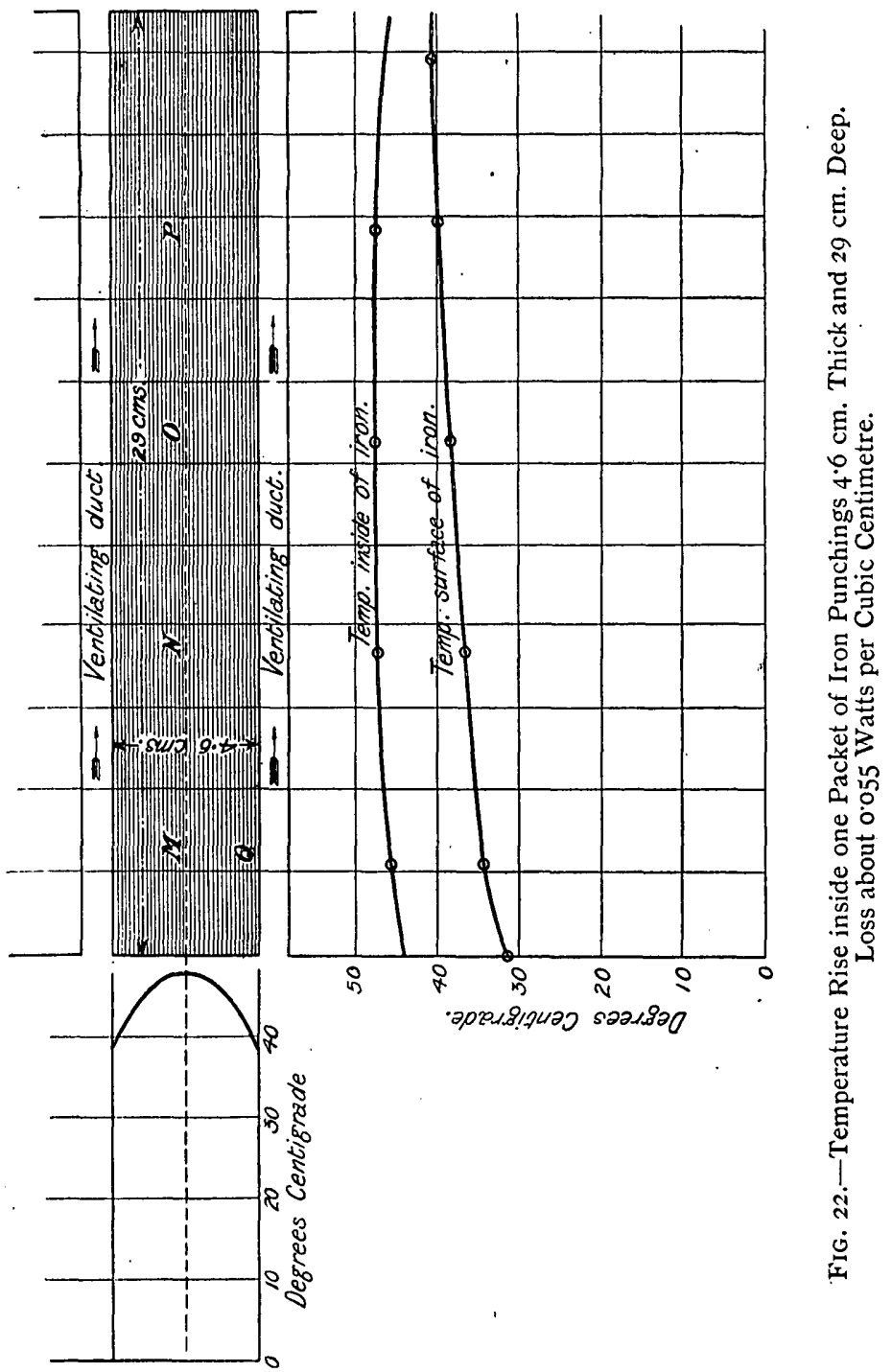

goes to raise the temperature to $53.2^{\circ}$ giving a total temperature rise of $3 I^{\circ} 5^{\circ}$.

The next point of interest is the distribution of temperature in the 
iron punchings. The thermo-couples were placed in the centre of a packet of punchings at the points $\mathrm{M}, \mathrm{N}, \mathrm{O}, \mathrm{P}$ (see Fig. 22), another couple was placed at $Q$ just behind the first punching in the packet ; the packet in question was the one between ducts 5 and 6 in Fig. I9. For the purpose of taking rapid readings of the temperature on the surface of the iron punchings within the ducts an instrument was made which consisted of a piece of copper foil $0.125 \times 0.75 \times 0.01$ in. soldered to a thermo-couple mounted on a velvet cushion, and arranged on a wooden rod so that it could be pushed down the ventilating ducts and pressed against the sheet iron. A spring was provided

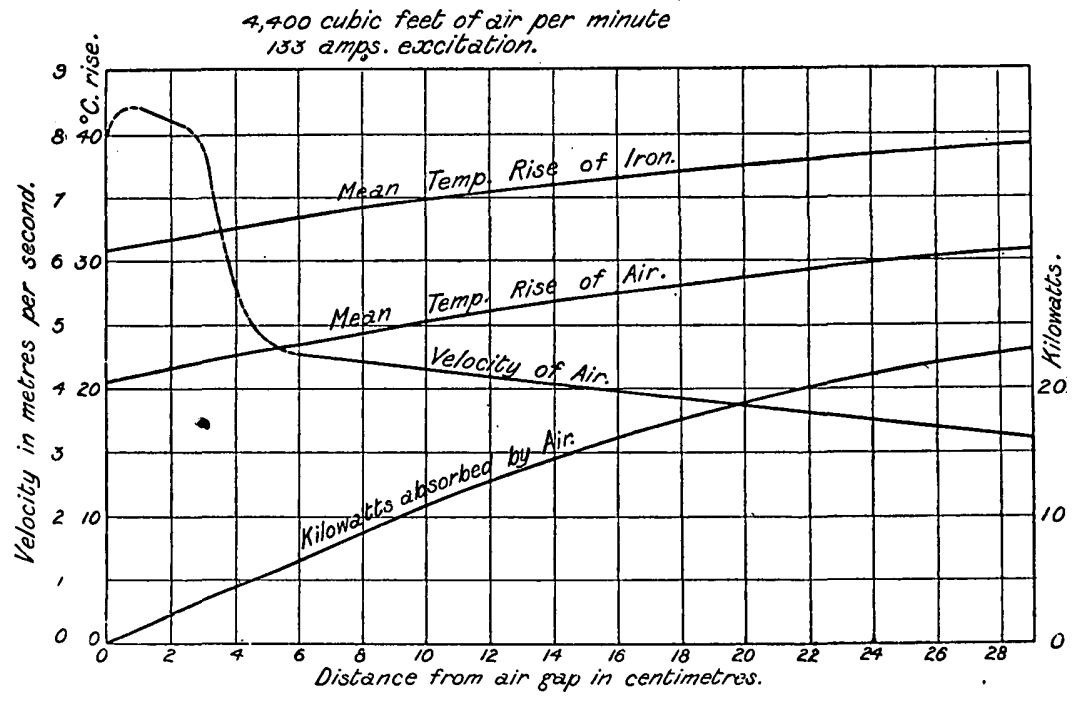

FIg. 23.-Curve showing how the Air is raised in Temperature as it passes along the Ducts and the number of Kilowatts absorbed.

at the back of the cushion to give the requisite pressure, the copper foil being shielded from draughts by the cushion, and being of small heat capacity very soon assumed the temperature of the iron against which it was pressed, thus one could read off directly on a millivoltmeter the temperature of any surface against which the copper foil was placed.

Fig. 2I gives the distribution of temperature of the iron on the surface of the various ducts in test A. The curves $\mathrm{H}, \mathrm{I}, \mathrm{J}, \mathrm{K}$, and $\mathrm{L}$ correspond with the positions in the ducts shown by the lines in Fig. I9.

It will be seen that the curves follow the general shape of the curves giving the rise of temperature of the air, but they are on the whole about ${ }^{\circ}{ }^{\circ} 5^{\circ}$ higher for the position $\mathrm{H}$ and $8^{\circ} 5^{\circ}$ for the position $\mathrm{L}$. 
If we take the average value of the temperature of the air at the position $\mathrm{H}$, then the average value at the position $\mathrm{I}$, and so on, and plot these average values, we get a curve giving the mean temperature rise of the air as it passes through the ventilating ducts, like that shown in Fig. 23. The ordinates in this figure give the rise above the tem-

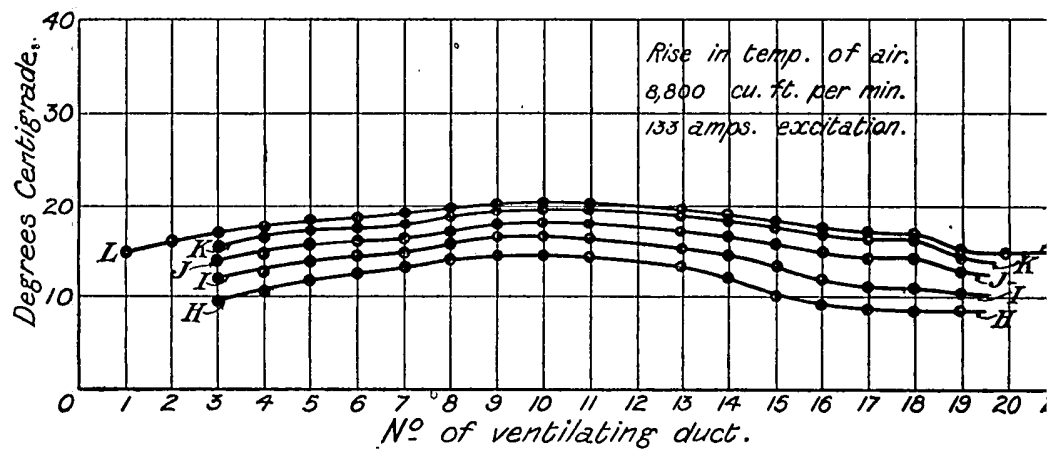

FIg. 24.-Rise in Temperature of Air with Air Supply doubled and Losses as before.

- perature at which the air enters the machine, the rise before reaching the ducts being $20^{\circ} 5^{\circ}$, and the rise in the ducts being $102^{\circ} \mathrm{C}$.

Taking similarly average values of the temperature of the iron at the various positions, we get a curve of temperature rise of the surface of the iron.

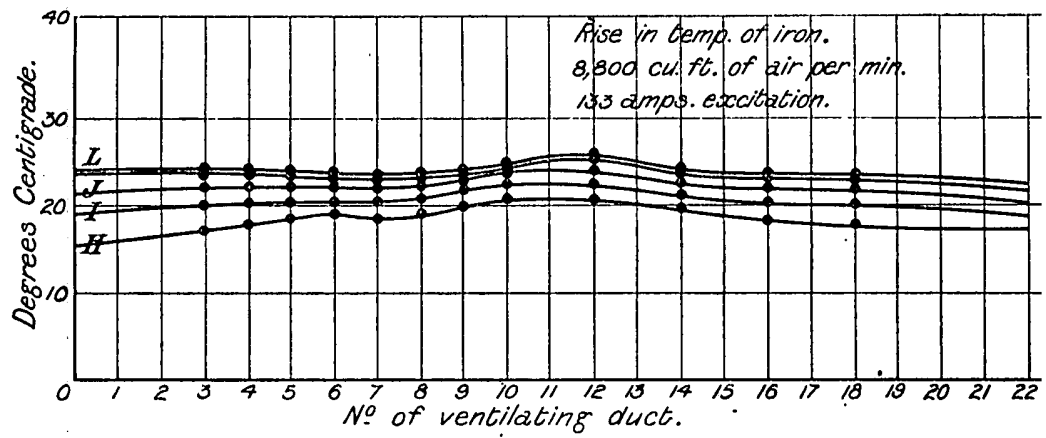

FIG. 25.-Rise in Temperature of Iron with Air Supply doubled and Losses as before.

As the total amount of air passing though the ventilating ducts was $300 \mathrm{lbs}$. per minute, it is possible to calculate the watts absorbed by the air from the rise in temperature by the formula-

$$
\text { Kilowatt }=\frac{300 \times 453 \times 0.2375 \times \text { temperature rise }}{60 \times 240} .
$$


Plotting the kilowatts absorbed by the air, we get the curve shown in Fig. 23. The velocity of the air in that part of the ventilating duct which was narrowed by the armature coils was 8.4 metres per second, in the part of the ventilating duct beyond the armature coils the velocity. was 4.5 metres per second, and at the exit of the ventilating ducts the vclocity fell to 3.2 metres per second. Plotting these figures we get

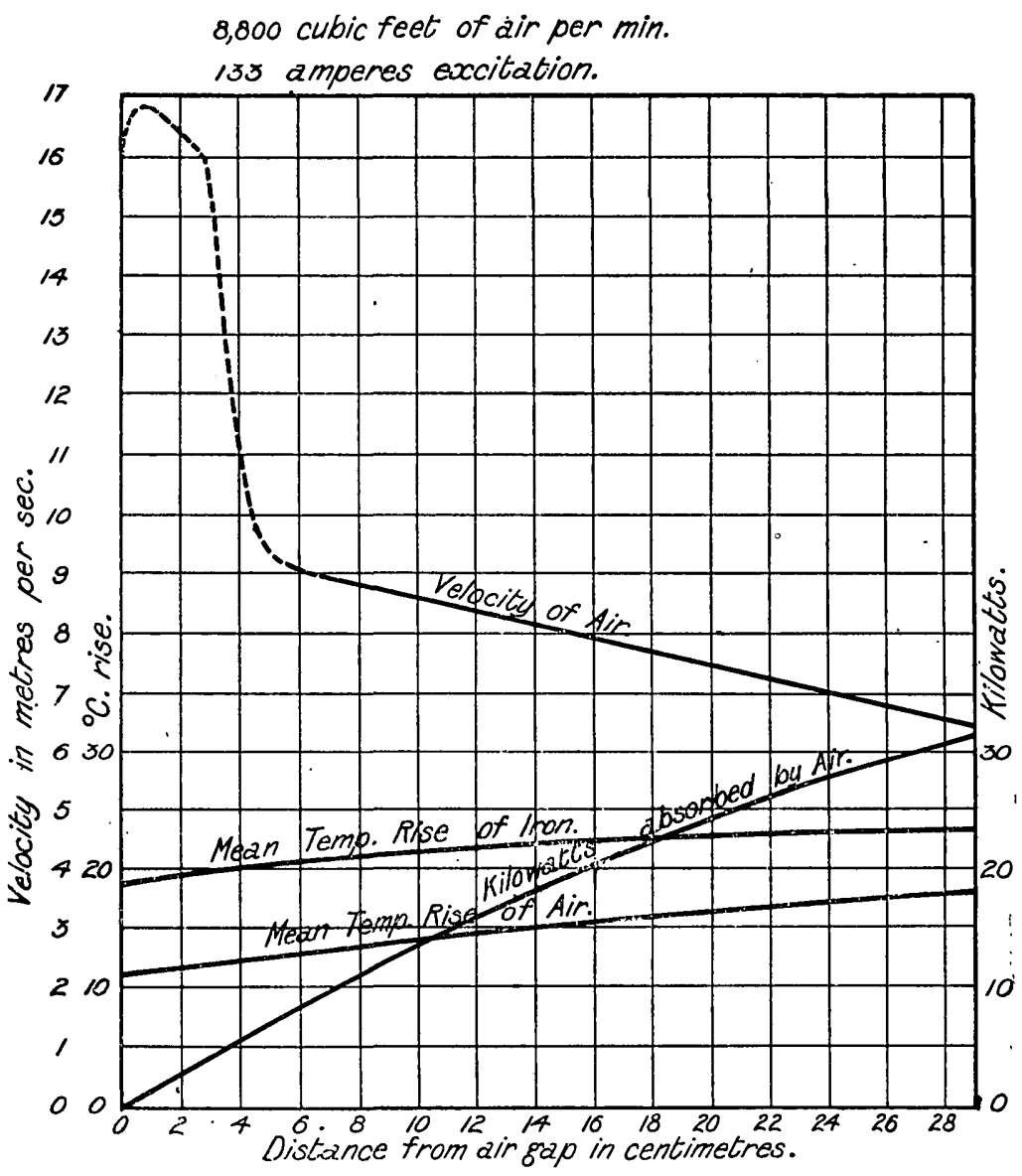

FIG. 26.

the velocity curve in Fig. 23. We have given on the same figure the difference of temperature between the iron surface and the air, the velocity of the air and the watts absorbed. If we take the slope of the curve giving the watts absorbed, say at a point $16 \mathrm{~cm}$. from the entrance to the duct, the slope of this line gives us the kilowatts absorbed by the air per centimetre travel. At the point of the $16 \mathrm{~cm}$. 
the rate is 800 watts per centimetre. The temperature difference between the air and the iron at this point is $9^{\circ}$, and the total area of the ventilating ducts to which the air is exposed in traversing the centimetre length of path is-

$$
(300 \times 2 \times 2 I)+(72 \times 2 \times 2 I)=15,600 \text { sq. } \mathrm{cm} .
$$

If we denote by $h$ the watts per square centimetre of cooling surface per ${ }^{\circ} \mathrm{C}$. difference of temperature between surface and air, we have-

$$
h=\frac{800}{9 \times 15,600}=0.0057 \text {. }
$$

This is at an air velocity of $3^{.95}$ metres per second.

In order to see the effect on the distribution of temperature throughout the machine with a greater draught, in test B the air supply was increased to 8,800 cub. $\mathrm{ft}$. per minute, the iron loss and excitation

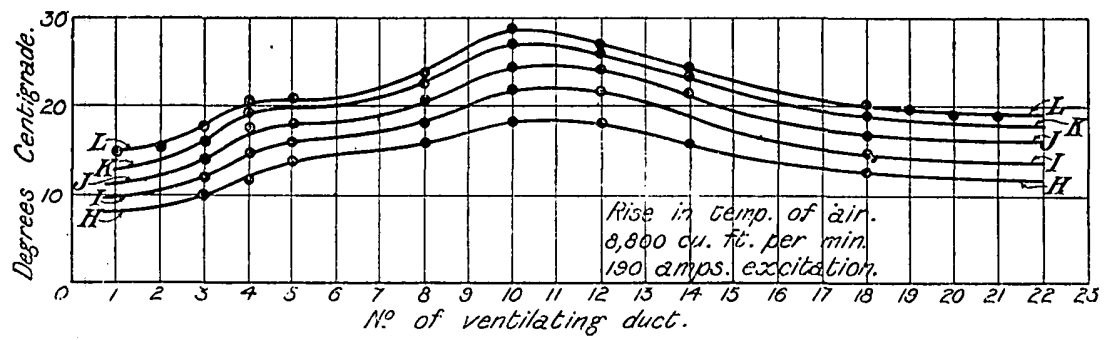

FIG. 27.-Rise in Temperature of Air Supply doubled and Iron Loss increased to $56 \mathrm{k.w}$.

losses being as before. The temperature of the air in various ducts is given in Fig. 24, and the temperature of the various parts of the surface of the ducts in Fig. 25. Plotting the average values of the air temperatures at different depths in the ducts, we get the curve marked "Temperature rise of air" (Fig. 26), and plotting the average values of the surface temperatures of the iron, we get the curve marked $"{ }^{\circ} \mathrm{C}$. rise of iron " (Fig. 26). On this figure is also plotted the velocity of the air as it passes along the ducts and the kilowatts absorbed by the air. Taking the tangent of the watts absorbed at the point $16 \mathrm{~cm}$. from the internal cylindrical face of the stator, we find that the air is picking up heat at the rate of $1,25^{\circ}$ watts per centimetre length of path. The difference of temperature between iron and air at this point is $7^{\circ} \mathrm{C}$., and the total area of surface exposed for $1 \mathrm{~cm}$. of path is $15,600 \mathrm{sq} . \mathrm{cm}$. as before; we therefore have-

$$
h=\frac{1,250}{7 \times 1,5600}=0.01146
$$

the velocity of the air being $7{ }^{\circ} 9$ metres per second. We see from 
these experiments therefore that $h$ (the watts per square centimetre of cooling surface per ${ }^{\circ} \mathrm{C}$. difference of temperature between surface and air) is almost exactly proportional to the velocity of the air. $h$, in fact, is given by the equation-

$$
h=0.00145 v,
$$

where $v$ is the velocity of the air in the ventilation duct in metres per second (see Fig. I3).

In test $C$ the air supply was maintained at $8,800 \mathrm{ft}$. per minute, but the iron loss was increased to $56 \mathrm{k} . \mathrm{w}$. and the excitation losses to I7.5 k.w. Under these conditions the temperature distribution of the air and iron in the ducts is given by Figs. 27 and 28 respectively. The

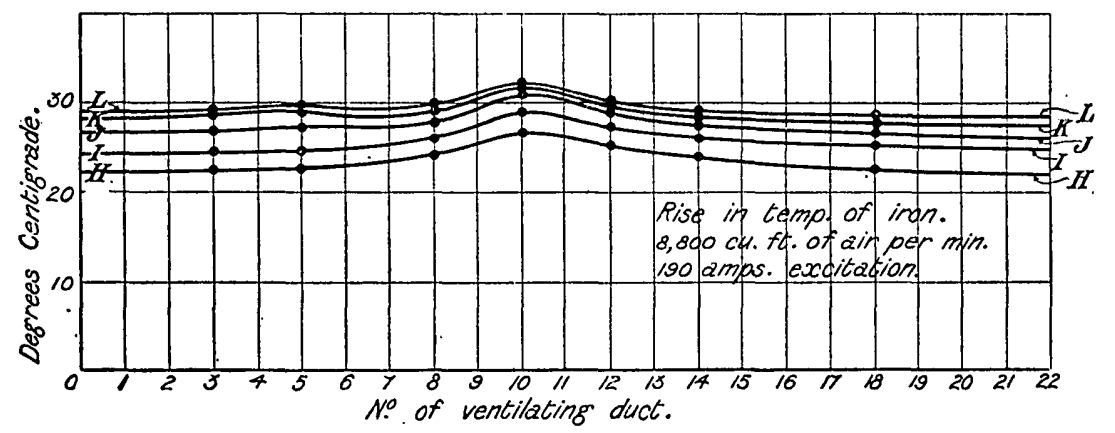

FIG. 28.-Rise in Temperature of Iron with Air Supply doubled and, Iron Loss increased to $56 \mathrm{k.w}$.

mean temperature rises of air and iron at different depths in the duct are given in Fig. 29. 'The watts absorbed by the air at different depths are also given on this Fig. 29.

\section{Conductivity of Iron Punchings.}

If we have a packet of iron punchings in which the loss per cubic centimetre is constant, and if all the heat generated is conducted across the packet and given off symmetrically to the air in the ventilating ducts which bound it on each side, the hottest part of the punchings will be in the centre, and the temperature gradient at any point within the iron will be proportional to $x$, the distance of the point from the centre. Let $w$ be the watts lost per cubic centimetre, then $w d x$ will be the loss in a little part of the iron laminations I sq. $\mathrm{cm}$. in area and $d x \mathrm{~cm}$. thick. The total heat generated in a block $\mathrm{I} \mathrm{cm}$. high and $\mathrm{I} \mathrm{cm}$. wide, and of length $x$ will be $w x$. If $\mathrm{K}_{h}$ is the heat conductivity in watts per square centimetre per ${ }^{\circ} \mathrm{C}$. difference of temperature per centimetre, the temperature gradient 
$\frac{d \theta}{d x}$ multiplied by the heat conductivity is equal to $w x$. As $\frac{d \theta}{d x}$ is negative when $x$ is positive we-

$$
\begin{aligned}
-\mathrm{K}_{h} \frac{d \theta}{d x} & =w x . \\
\theta & =\text { constant }-\frac{w}{2 \mathrm{~K}_{h}} x^{2} .
\end{aligned}
$$

The curve of temperature distribution within the iron is therefore a parabola such as that plotted in Fig. 22.

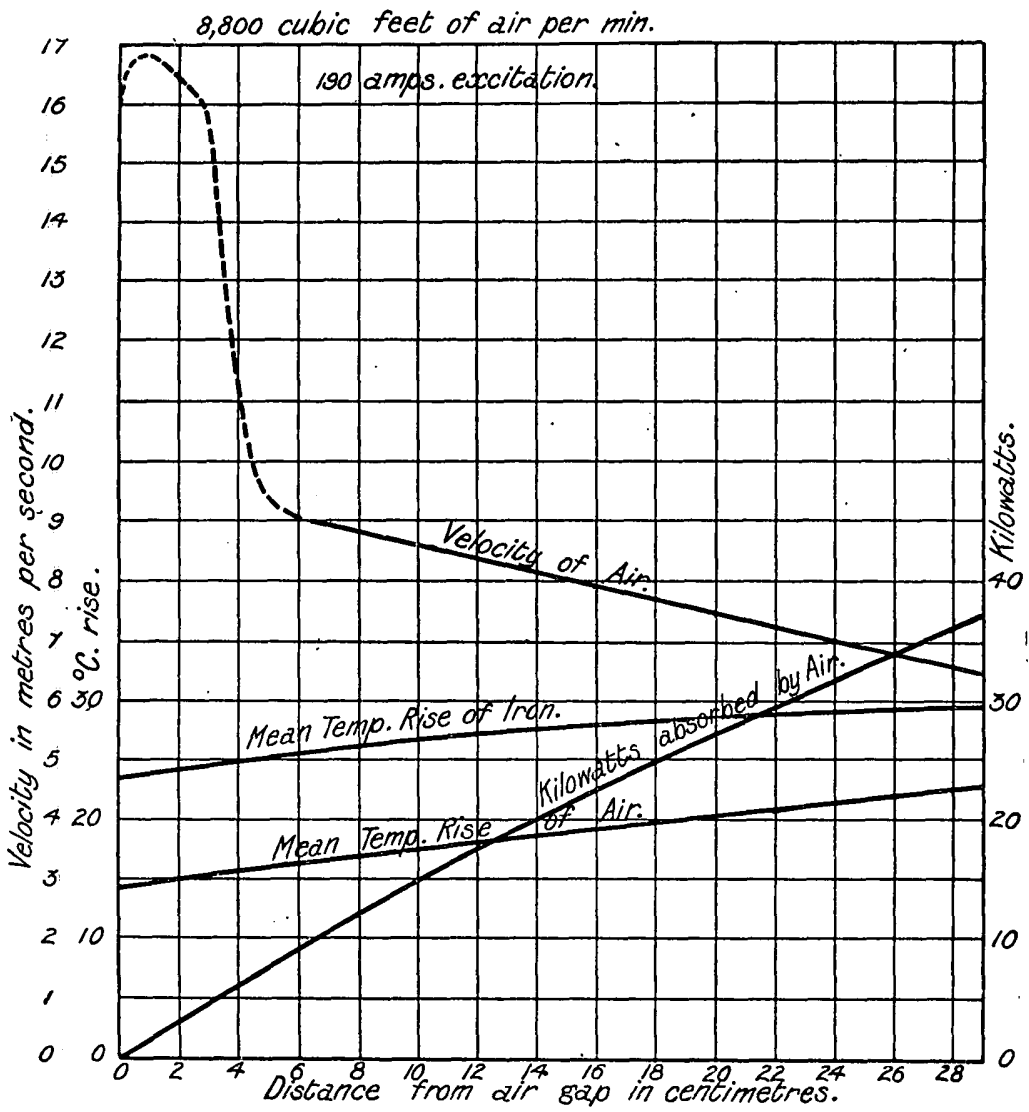

FIG. 29.

In the experiments above described measurements were made of the temperature in the centre of the packet and on the exterior. Knowing the loss per cubic centimetre of iron we can calculate $\mathrm{K}_{h}$ as : follows :- 
The total iron loss amounted to $43.5 \mathrm{k} . \mathrm{w}$. Of this $4.5 \mathrm{k} . \mathrm{w}$. was in the teeth, and $39 \mathrm{k.w}$. behind the teeth. The total volume of iron behind the teeth was $710,000 \mathrm{cub} . \mathrm{cm}$.

Thus-

$$
\frac{39,000}{710,000}=0.055 \text { watt per cubic centimetre }=w .
$$

It is seen from Fig. 22 that the temperatures on the medial line between $\mathrm{P}$ and $\mathrm{N}$ were almost constant for points on both sides of $\mathrm{O}$, so that the amount of heat conducted from $\mathrm{O}$ towards $\mathrm{P}$ and $\mathrm{N}$ would not be very great. It would not be negligible because the conductivity of the punchings in this direction is so much greater than the conductivity across the laminations. Let us take the figures at the point $O$, where the heat conducted along the laminations is at a minimum, and calculate the conductivity on the assumption that all the heat flows to the walls of the ventilating ducts.

Now there are $8^{\circ}$ difference of temperature between the centre and the surface of the packet, so we have-

$$
\begin{aligned}
3^{8} & =46-\frac{0.055}{2 \mathrm{~K}_{h}} x^{2} \text { (see Fig. 22). } \\
8 & =\frac{0.055}{2 \mathrm{~K}_{h}}\left(2^{2} 25\right)^{2} . \\
\mathrm{K}_{h} & =0^{\circ} .0174 \text { watts per square centimetre per }{ }^{\circ} \mathrm{C} \text {. per centimetre. } \\
\mathrm{K}_{q} & =0.0042 \text { calorie per second per square centimetre per }{ }^{\circ} \mathrm{C} . \\
& \text { per centimetre. }
\end{aligned}
$$

The formula given by $\mathrm{Dr}$. Ott for the heat conductivity across laminations is-

where-

$$
\mathrm{K}_{q}=\frac{\delta_{\mathrm{x}}+\delta_{\mathrm{z}}}{\frac{\delta_{\mathrm{r}}}{\mathrm{K}_{\mathrm{I}}}+\frac{\delta_{2}}{\mathrm{~K}_{2}}+\frac{\mathrm{I}}{a}},
$$

$\delta_{\mathrm{t}}=$ thickness of iron in centimetre.

$\delta_{2}=$ thickness of insulation in centimetre.

$\mathrm{K}_{\mathrm{s}}=$ conductivity of iron $=0.15$.

$\mathrm{K}_{\mathrm{z}}=$ conductivity of insulation (paper $=0^{\circ} 0003$ ) (varnish $=0^{\circ} 0006$ ).

$a=$ conductivity of rough surface. This may be between 0.5 for smooth and $0^{\circ} 04$ for very rough iron.

In our experiments $\delta_{1}=0^{\circ} 04 \mathrm{I}, \delta_{2}=0^{\circ} 0033$, the insulation being paper. The formula gives $\mathrm{K}_{q}=0^{\circ} 0035$.

In the experiments described the loss per cubic centimetre, 0.055 watt, was rather high. This was because the machine was run at 30 per cent. above its normal field excitation. A more usual figure for 50 cycles would be 0.045 watt per cubic centimetre. If then we take the conductivity of the punchings at 0.0174 watt per square 
centimetre per ${ }^{\circ} \mathrm{C}$. per. centimetre we have $\theta$, the difference in temperature between the surface and middle of the packet-

$$
=\frac{0.045}{2 \times 0.0174} x^{2}
$$

For a packet $4.5 \mathrm{~cm}$. thick $\left(x=2^{\cdot} 25\right)$ the excess of temperature would be $6.5^{\circ} \mathrm{C}$. and the mean temperature of the iron above the surface only $45^{\circ} \mathrm{C}$.

At 25 cycles the loss per cubic centimetre would be about 0.025 watt per cubic centimetre. Here the packets might be about $6 \mathrm{~cm}$. thick for the same temperature rise in the hottest part.

In any case, it is seen that unless the packets are made much thicker than is usual in practice the temperature rise in the centre due to the poor heat conductivity across the laminations is not of very great importance.

\section{Conclusions.}

We see, then, that in arranging for the cooling of large electrical machines the following matters must be taken into account :-

I. Sufficient air must be provided to carry away the heat generated. If IIoo cub. ft. of air per minute is provided for each kilowatt loss it will in general be sufficient. If the conductivity for heating of all parts is - sufficiently good and the air is so distributed that none of it receives a temperature rise greater than $32^{\circ} \mathrm{C}$. it may be that 60 cub. $\mathrm{ft}$. of air per minute would be sufficient to keep the machine below $45^{\circ} \mathrm{C}$. rise.

2. Sufficient cooling surface must be provided to communicate the heat to the air.

3. For ventilating ducts we may take the formula-

$$
h_{v}=0.0014 v \text {. }
$$

Where $h_{v}$ is the watts per square centimetre of cooling surface per ${ }^{\circ} \mathrm{C}$. the difference of temperature between surface and air and $v$ is the mean velocity of the air in the duct in metres per second.

4. For the cooling of the surface of rotors and the internal cylindrical face of stators we may take the formula-

$$
t^{\circ}=\frac{333 \times \text { watts per sq. } \mathrm{cm}}{\left(\mathrm{I}+\mathrm{O}^{\circ} \mathrm{I} v\right)} .
$$

5. To find the difference of temperature between an armature coil and the surrounding iron one can adopt the method given on page 682 , using the constants for the heat conductivity of the insulated material given in Table II., and allowing for air-spaces whose resistance is given roughly by Fig. 5 .

6. To find the temperature rise of the surface of wire-wound coils upon which the air is blowing with a velocity of $v$ metres per second we may take the formula-

Vor. $4 \dot{8}$.

$$
h_{d}=0.00 \mathrm{II}\left(\mathrm{I}+0.54 v^{2}\right) .
$$


7. To find the difference between the inside of a wire-wound coil and the external surface we may follow the method given on page 695 .

8. 'To find the difference between the temperature of the centre and the cooler parts of a hot-bed of conductors cooled mainly by the conduction of the heat along the conductors we must adopt the method given on page 686 .

In conclusion, we wish to express our indebtedness to Mr. H. M. Evans and Mr. R. D. Hobden for their diligence in conducting some of the most tedious parts of the investigations, and to Mr. S. G. Nottage for the work he has done in plotting the results. We also wish to express our thanks to the British Westinghouse Company for the facilities they have given us in carrying out the experiments and for their permission to publish the results.

\section{Discussion.}

Mr. Law.

Mr. A. H. LAlv: The points which the authors have brought forward must be of the very greatest interest to every designer. Table II., I think, is particularly interesting, although a certain amount of the ground has been covered before by work done elsewhere. Perhaps the most interesting thing is the relatively small difference between the results in column IO. I think if any of us had not these results before us we should have been inclined to say that the difference in the thermal conductivity of different insulating materials would have been greater than this. The lowest and the highest figures are both for mica compounds. The lowest figure contains r9 per cent. of shellac, and the highest figure is practically pure mica, so that probably for ordinary commercial working we can take a figure about half-way between the two, which brings the figure for mica very much in line with the figures for other materials. In the same way with regard to the varnished empire cloth, which is the next highest figure, probably in actual practice it would not be possible to press it as tightly as has been done in this experiment, and consequently perhaps that figure would be slightly reduced. As a result it appears that the difference in the thermal conductivity of different insulating materials if used intelligently is not very great. I was very much interested in the various methods of ventilation describeed and illustrated in the figures, particularly in Fig. I8, which I understand is the same type of machine as that on which all the experiments were made in the later part of the paper. I have used this system of ventilation in a number of large machines almost identical with that shown in Fig. 18 , that is, in plants up to 6,000 k.w., in the larger alternators using a screw fan in place of a centrifugal fan. The question of fans on large alternators is certainly rather a vexed one, owing to the difficulty of getting high efficiencies for the fans. As far as I can make out in the experiments donc on the 1875 kilovolt-ampere plant of the authors, the efficiency of the fan with a small quantity of air was in the neighbourhood of $2+$ per cent., and of the 